\title{
A Pragmatic Approach for Evaluating and Accrediting Digital Competence of Digital Profiles: A Case Study of Entrepreneurs and Remote Workers
}

\author{
Juan Bartolomé ${ }^{1}$ (D) Pablo Garaizar ${ }^{2}$ (D) Xabier Larrucea ${ }^{1}$ (D)
}

Accepted: 13 April 2021 / Published online: 29 April 2021

(c) The Author(s), under exclusive licence to Springer Nature B.V. 2021

\begin{abstract}
During the last decades, digital competence has become essential at workplace. Nowadays, it is difficult to find a job where no ICT skills are required. At the same time, there is a lack of ecosystems for adult reskilling in digital competence. Moreover, most of them do not use of a common language and terminology, decreasing the possibilities of being used by a wider public. In addition, the assessment of digital competence cannot be done using simple self-assessment tests, but more complex tools such as simulations or other activities based on real scenarios. Considering this, we designed a performance-based evaluation system following a pragmatic approach based on DigComp framework. We carried out a needs analysis based on expert consultation (63 teleworkers and 82 entrepreneurs) to create an assessment syllabus and implement the assessment modules. Then, we conducted an analysis by experts $(n=21)$ of the relationship between the content of the tests and the construct it was intended to measure. After refinement, the system was piloted by end-users all over Europe $(n=525)$. Results confirmed that DigComp was the most appropriate reference when considering the transversality of digital competence, providing researchers with well-defined clear criteria.
\end{abstract}

Keywords Digital competence · Assessment · DigComp · Digital profiles · Entrepreneur · Teleworker

Juan Bartolomé

juan.bartolome@tecnalia.com

Pablo Garaizar

garaizar@deusto.es

Xabier Larrucea

xabier.larrucea@tecnalia.com

1 TECNALIA, Basque Research and Technology Alliance (BRTA), Derio, Bizkaia, Spain

2 Faculty of Engineering, University of Deusto, Bilbao, Spain 


\section{Introduction}

Digital technologies such as online collaboration platforms, office suites and mobile devices, are integrated not only in most workplaces but also in everyday life (Cascio \& Montealegre, 2016). This digital shift is generating an enormous impact on the skills needed for most jobs due to the automation of regular tasks, the creation of new and different types of jobs, or the need for more skilled ICT professionals in all sectors. Digital technologies are the main drivers of innovation, growth and job creation in the global economy. However, incorporating such technologies is not enough to assure success (Schallenmueller, 2016). Previously, the focus was on facilitating the availability and access of technology; but during the last years, special efforts have been made to avoid citizens' exclusion from basic services in society and to ensure universal access to information (Van Deursen \& Helsper, 2015). Digital literacy (also known as digital fluency) reflects an employee's proficiency and comfort in achieving desired outcomes using technology and it is one of the key abilities, especially relevant in today's work environment (Colbert et al., 2016). However, knowing how to use some programs or applications is not enough. Problem solving skills in technology-rich environments are highly relevant, especially since ICT has permeated all kinds of activities. They are a key factor to avoid social and labor exclusion, where the educational level, non-formal education, and the use of different skills (reading, numerical, related to ICT) are decisively related (Iñiguez-Berrozpe \& Boeren, 2019). The digital competence of the workforce plays a relevant role in the determinants of technology adoption (Marsh, 2018), but it is considered as a skill that evolves (Mohammadyari \& Singh, 2015). Thus, employees' digital skills are important to be updated to enable both individuals and organizations to take advantage of the digital workplace and progress in their professional careers. At the same time, most jobs are undergoing a fundamental transformation in the skill sets required to do them and by 2022, 54\% of existing workforce will need upskilling or reskilling (Schwab, 2018; Voogt et al., 2013). Mobile, personalized and ubiquitous everyday interactions brought by smart phones should be urgently addressed by training initiatives for developing digital literacy (Baruch \& Erstad, 2018).

The digital sector -and, especially, e-skills- have been at the top of the European agenda since 2014 with the Digital Single Market (DSM) as one of its priorities (EC, 2015). The New Skills Agenda for Europe is one of the most important tools to make the right training, skills and support available to people in the EU (European Commission, 2016). Digital Skills and Jobs Coalition is one of these initiatives with the goal of improving the digital skills of the wider population, not just IT professionals (European Commission, 2017b). Nevertheless, $44 \%$ of the European population does not have any basic digital skills, although 9 out of 10 jobs will require digital competences soon (The Digital Skills Gap in Europe, 2017). According to the Digital Economy and Society Index (DESI), there was a lack of 500.000 experts in 2020 in the ICT (Information and Communication Technology) sector (EC, 2016b). Despite progress in this problem, Europe is still lacking the digitally skilled workforce needed.

The Occupational Information Network $\left(\mathrm{O}^{*} \mathrm{NET}\right)$ database provides detailed descriptions of occupations, displaying each profile with the importance of the skills required for that job (Handel, 2016; Peterson et al., 2001). This tool also indicates the level of proficiency required for each skill, but it does not use a reference framework for the digital competences identified. At European level, the European multilingual classification of Skills, Competences, Qualifications and Occupations (ESCO) provides the necessary common vocabulary to facilitate the exchange of information related to skills and qualifications, 
and has directly implemented DigComp: the Digital Competence Framework for citizens (Ferrari, 2013) in the definition of essential knowledge and skills for the list of occupations provided (European Commission n.d.). However, ESCO does not indicate the level of skills required. Finally, entrepreneur and teleworker profiles are not available in O*NET or ESCO, probably because such transversal profiles can be found as part of more specific occupations.

From a practical perspective, the definition of a system to measure workers' level of digital competence based on their roles and functions (i.e. different digital profiles) could be a useful tool to increase the digital competence of different professions. However, the definition of which digital competences are essential for teleworkers or entrepreneurs to meet future needs has not been directly tackled.

This paper is organized as follows. First, we introduce the background of the accreditation and assessment of digital competence. Then, we present the entrepreneur and teleworker digital profiles plotting the development of the digital competence for both profiles. Section 3 describes the methodology followed in this study, while Sect. 4 summarizes the results. Finally, we discuss results and future directions.

\section{Accreditation and Assessment of Digital Competence}

\subsection{Digital Competence}

Until recently, there was no common understanding of what digital competences are and which of them should be necessary for every citizen (Ala-Mutka, 2011). DigComp (Ferrari, 2013) and its updates (Carretero et al., 2017; Vuorikari et al., 2016) were launched by the Institute for Prospective Technological Studies (JRC-IPTS) of the European Commission with the aim to contribute to the better understanding and development of Digital Competence in Europe (Janssen et al., 2013) and the following objectives: (1) Identify the key components of digital competence in terms of the knowledge, skills and attitudes needed to be digitally competent; (2) develop the descriptors of digital competence in order to feed a conceptual framework and / or guidelines that can be validated at European level, taking into account the relevant frameworks currently available (Ferrari, 2012); and (3) propose a roadmap for the possible use and revision of the Digital Competency framework and descriptors of digital competences for all levels of learning. Later, version 2.0 of the framework defined 8 proficiency levels for each digital competence instead of 3 (Vuorikari et al., 2016), providing a more detailed description of the characteristics of each level (in terms of knowledge, skills and attitudes) and requirements for progressing to the next level. Indeed, this contribution can be of special interest for the definition of accreditation pathways for digital profiles which require specific digital competences and levels. All in all, DigComp was proposed to create a European consensus on the components of digital competence by developing a conceptual framework that could serve as a reference for current initiatives, curricula and certifications.

There are several concepts closely related to digital competence addressed from different perspectives (e.g., European Parliament, European Council, European Commission, etc., see Ala-Mutka, 2011). The term digital literacy is defined as "the skills required to achieve digital competence [...] is underpinned by basic technical use of computers and the Internet." (European Parliament and the Council, 2008b). Digital literacy is a wide term that covers not only the skills but also the knowledge and attitudes towards technology. 
Similarly, the term e-Skills covers the different levels of ICT skills: ICT user skills, ICT practitioner skills, and e-Business skills. It is the concept used by DG Enterprise and Industry and ICT industry. Other close term is "media literacy", defined as the ability to access the media, to understand and to critically evaluate different aspects of the media contents, and to create communications in a variety of contexts. This concept is used by European Commission to underline tool-related skills, critical attitude and understanding of safe usage. In this context, "digital competence" involves "the confident and critical use of Information Society Technology (IST) for work, leisure and communication. It is underpinned by basic skills in ICT: the use of computers to retrieve, assess, store, produce, present and exchange information, and to communicate and participate in collaborative networks via the Internet." (European Parliament \& the Council, 2006). Finally, there are also other concepts related to digital competence such as "Computer literacy", "Internet literacy", "Information literacy", "ICT literacy", and "Digital fluency". Considering that the definitions for digital competence diverge with a complex scenery of definitions and concepts, Ala-Mutka (2011) defined digital competence for DigComp as an emergent literacy from other literacies, which include the concepts listed previously. The DigComp framework defines the scope and the components of digital competence for citizens providing an overall, complete and shared understanding of what digital competence is. It classifies digital competence in 5 competence areas: (1) information and data literacy, (2) communication and collaboration, (3) digital content creation, (4) safety and (5) problem solving. The DigComp framework provides competence descriptions in general terms and is technologically neutral. Stakeholders should carry out their own implementations according to their requirements, identifying which specific digital devices or software applications are relevant for them. We decided to use DigComp because it fits our study, providing a common vocabulary and being flexible enough to adapt it to different digital profiles. Moreover, it also prevents the rapid obsolescence of the framework and consequently the digital profiles defined in our study.

\subsection{Accreditation and Assessment}

The recognition of digital competence as a transversal component that supports other key competences is one of the key points in connection with the adoption of a single reference framework of digital competences, the creation of guidelines and competency profiles, the promotion of the recognition of competences acquired in non-formal and informal environments and the development of evaluation tools as illustrated by CEDEFOP (2015) or in the Erasmus + Programme (European Commission, 2019). Consequently, many systems of the so-called 'high-stakes' assessment are currently used for the evaluation and certification, using different approaches and most of them based on self-assessments, not covering all the digital competences, and focused on low-order cognitive skills (Kluzer \& Priego, 2018; Siddiq et al., 2016; Stödberg, 2012).

Despite the growing need for adult reskilling, opportunities for broad-based and inclusive reskilling are currently not available at the appropriate levels of access, quality and scale of supply in most countries. Low-cost digital training across many countries does not suffice to provide an integrated system which addresses the diverse needs of learners, dedicates enough resources, and brings together the right stakeholders in providing applied learning opportunities. In addition, different stakeholders might contribute to building an ecosystem for adult reskilling, including key pathways such as to take stock of and recognize existing skills, or to understand skills demand (World Economic Forum, 2017). Skills 
demand is evolving rapidly at an aggregate industry level then the degree of changing skills requirements within job categories and occupations is even more pronounced. However, the there is no specifications for designing systems for adult reskilling based on a common language and terminology. Most of the digital literacy frameworks adopted are based on training courses and assessment frameworks used by commercial enterprises. Law et al. (2018) identified that 36 out 47 countries adopted enterprise frameworks: ICDL $(n=31)$, IC $^{3}(n=13)$, and Microsoft Digital Literacy Standard Curriculum $(n=11)$. Consequently, the digital competences training and assessment tools are strongly influenced by the framework chosen.

These commercial frameworks are focused on professional certifications, not free and mainly based on commercial software such as Microsoft Office and Microsoft Windows. Regarding their scope, they are mainly focused on employability and workplace functional skills. However, they do not implement cognitively complex activities, mainly putting in practice descriptors from the basic and intermediate levels. ICDL is the most relevant amongst the enterprise frameworks and the most complete solution. It provides a technical solution based on a commercial software which interacts with the operating system and the applications installed on your computer. Users are asked to perform real tasks, but the assessing environment has serious limitations; It only works on Microsoft Windows and Microsoft Office which could not be the case of many organizations where other office suites coexist such as G Suite by Google (Gilbert, 2019). Furthermore, their certifications are tool oriented and specially focused on workstations (computers and laptops). According to Eurostat (2017), in $201765 \%$ of individuals aged 16-74 within the EU-28 used a mobile device to connect to the Internet. Therefore, excluding mobile devices from this framework could be a significant limitation. Fortunately, the arrival of DigComp facilitated the development of custom implementations by different types of organizations (Kluzer \& Priego, 2018). Considering that descriptive rather than prescriptive nature of the framework, stakeholders must adapt it to the requirements of their implementations. The DigComp framework has been used for a variety of pragmatic purposes. These models suit well the purpose of professional accreditation, which is one of the objectives of our study. However, it is quite challenging to come up with a scientifically reliable and valid performance-based test that measures the 21 competences of DigComp on 3 proficiency levels. As an alternative to a pragmatic approach, could be a psychometric approach such the recent implementations guided by Multidimensional Item Response Theory (MIRT) that understands digital literacy as a single latent trait that should be inferred indirectly through the statistical analysis of the test results. Unfortunately, the assumption of local independence might be quite difficult in case of authentic performance-based assessment. The pragmatic approach tends to result in weaker internal validity, but better external validity of the assessment instrument, as it is better understood, accepted and adopted by various stakeholders. Consequently, we had to address the challenge of balancing internal and external validity, both through methodological considerations and the design of the assessment instrument. We did not aim for high reliability and internal validity; instead, we prioritized external validity and the perceived usefulness of assessment to the participants. Considering the aim of our study and the requirements, we decided to follow a similar approach like the one suggested for DLGF by Laanpere (2019).

Regarding the frameworks developed based on DigComp identified and analyzed by Kluzer and Priego (2018), only a few of them address competence assessment, recognition and certification, including the development of computer-based assessments (CBA). CBA have an enormous potential providing innovative and authentic item formats, and the possibilities to obtain information on test-takers' behavior (Greiff et al., 2015; Osborne et al., 
2013; Timmis et al., 2016). According to Binkley et al. (2012), computers are needed for evaluating the people in true-to-life settings, such as those offered by simulated environments, necessary for measuring skills such as problem solving, information literacy and collaboration. Bennett and Bejar (1998) proposed a model where computer-based assessments can be considered as an integrated system compounded by interrelated components. Kuo and $\mathrm{Wu}$ (2013) applied and elaborated that model, exploring the patterns of technology applications, targeting the categories where technology applications bring advantages and new opportunities. Considering this, we used this framework to guide our analysis to identify potential applications of technology, particularly in the development of new types of assessment items measuring higher order skills beyond multiple choice questions. We also examined the design adopted for the implementation of the tests based on DigComp, and finally how the definition of digital profiles was addressed. Most of the assessment tools analyzed are online tests based on self-reporting, comprised by multiple choice questions and Likert scales, where only the knowledge and attitudinal component of the digital competence are considered. Only a few of them include simulations or task-based assessments where participants must interact with the workstations (BAIT n.d.; IKANOSTEST n.d.; PIX n.d.; TUCERTICYL n.d.). We analyzed these cases more thoroughly since they are totally aligned with the aim of our study. The main objective of these assessment tools is not to evaluate the skills related to specialized computer tools, but to provide the elements to understand any digital environment in an effective way. Their approach provides the most accurate view of users' competence because they must put their knowledge in action. IKANOSTEST (n.d.) provides a self-diagnosis test too, structured in 3 thematic blocks which include a series of aspects relating to ICT: (a) developing potential, (b) studies and certifications, and (c) digital competences. Its aim is to identify users' strengths and areas for improvement and to create a formative experience by interpreting the results. In addition, BAIT (n.d.) and TUCERTICYL (n.d.) include a demo test with instructions before taking a test, where participants can practice with questions similar to those included in the certification test. PIX (n.d.) offers a self-diagnostic test per competence area implemented using an adaptive algorithm, which aims to identify users' levels per competence area before taking a certification test. Users can select the competences to include in the test and the algorithm adapts the level of the tests according to their answers. All these tools considered different non-PC devices when implementing the evaluation items. Moreover, they implemented the skills items mainly using two compatible alternatives: simulations and real tasks to be carried out in the workstations. Simulations were implemented using Articulate Storyline software, an application to create technology-based learning media (Siegel and Hadi, 2017). Participants must evaluate a given situation and interact with interactive images simulating screens and actions with different applications to reach to the final solution. Real tasks were implemented creating custom developments where participants interact with their workstations to carry out the instructions given in a statement, e.g. download a template, implement a list of instructions, or upload the final document to the platform to be automatically evaluated. Most of these items were integrated in the platform using libraries and Application Programming Interfaces (APIs) in order to be expanded and consumed by other platforms.

There are different approaches for the implementation of the tests. TUCERTICYL (n.d.) offers two certifications: foundation and medium citizens. In each certification, all the competence areas are included (about 63 questions per test). PIX (n.d.) only evaluates 16 competences. These tests only include the skills assessed as level 1 or more in the pretest task. BAIT (n.d.) is currently providing the certifications per digital competence to the public workers of the Basque Government, but also has implemented certifications based 
on competence areas. The decision of which approach should be chosen is based on the depth of knowledge and skills which it is needed to be measured. Tests based on competence areas does not asses all the learning outcomes due to the number of items involved. If BAIT tests are based on digital competences, the requirements of the certifications can be increased, including more items and covering more learning outcomes.

Regarding the definition of digital profiles, only BAIT (n.d.) pays attention to this issue defining profiles where users can assess their digital competences and then compare their results with the levels required in the digital profile. This approach is totally aligned with the aims of our study and was taken as inspiration. Apart from BAIT (n.d.), only a few focused on specific profiles, with self-assessments for university students in the first year of nursing (Evangelinos et al., 2014), citizenship and employees of both private and public organizations (Digital Competence Wheel n.d.), employees and companies (SMARTIVEMAP n.d.), and employees and managers of the Dutch region (Digitale interaktive Didaktik n.d.).

In order to implement an effective assessment of users' skills, they must be able to practice them in real environments and then assessed through relevant and authentic evaluations (Litchfield \& Dempsey, 2015). Most of the assessments found in the literature, have a technology literacy focus with multiple-choice and constructed response items (Sparks et al., 2016). They provide a technologically simple solution, but most of them tend to misjudge the abilities of participants due to the intrinsic positive bias partly caused by users' over-confidence (Kruger \& Dunning, 1999; Pajares \& Graham, 1999). Although the strength of participants' ICT self-efficacy and motivation to use ICT are important for good performance in ICT related tasks (Guillén-Gámez et al., 2018), the bias and accuracy of participants' ICT self-efficacy are evenly relevant. Therefore, these biases should be taken into account to improve the validity of these solutions and their predictive capability (Aesaert et al., 2017). However, there is a conceptual ambiguity in the definitions and the operations of the assessment methods, and a tendency to measuring only low components of the ICT skills according to the Bloom's Taxonomy (Siddiq et al., 2016). Besides, these tools do not completely cover the 5 DigComp competence areas.

Digital competence is an observable expression of knowledge, skills and attitudes deployed by people in an integrated way. In order to accurately evaluate their level of competence, people should be observed while performing tasks with different levels of difficulty. Previous studies have emphasized that competence in digital literacy requires attitudes, knowledge and skills. We decided to leave the assessment of the attitudinal component of the digital competence out of the scope of this study due to the complexity and the lack of consensus evaluating it.

Assessment instruments can be used in a wide range of contexts (individuals or groups, accreditations, certifications, etc.). According to Carretero et al. (2017), assessment tools comprise: (a) self-assessment, subjective evaluations which may not really reflect an individual's competence; (b) knowledge-based assessment, which measures the knowledge of an individual in a certain subject or field; (c) performance-based assessment, where an individual has to demonstrate their ability performing certain tasks; and (d) secondary data-gathering and analysis, which provides information related to a group but not at the individual level.

Most of the accreditation and certification systems have followed a performance-based approach (Law et al., 2018). Our main goal was to measure if participants were able to put their knowledge into action performing certain tasks. However, we decided to design these tasks not focused on specialized computer tools (e.g., Microsoft Word/Google Chrome), but on a wider set of digital environments. Therefore, we followed a performance-based 
approach through real or simulated tasks. Performance-based assessments represent a set of strategies for evaluating knowledge, skills and work habits through the performance of tasks that are meaningful and attractive to users. Users have to access to materials, interact with programs and services, create new contents, search and evaluate the information found, and communicate and share information (Kruger \& Dunning, 1999). Although the core competencies formulated in DigComp can remain stable over time, in the current context of technological evolution, the construction of digital competence cannot be represented as a fixed entity (Aesaert et al., 2014; Siddiq et al., 2016). Therefore, the descriptors of the digital competences require a constant revision and the same happens with its evaluation systems. Furthermore, Litchfield and Dempsey (2015) suggested that the concepts and constructs for the assessment of ICT skills should be carried out from a domain perspective (ICT, twenty-first century, etc.) or a knowledge perspective (literacy, competence, etc.).

Finally, validity represents how test results can be interpreted and used according to the objectives pursued in the evaluation (American Educational Research Association, American Psychological Association, and the National Council on Measurement in Education 1999). In the context of the test, internal validity represents how an evidence supports a claim about cause and effect, while external validity can be understood as its potential to apply the conclusions obtained to outside the other contexts outside the study. The pragmatic approach based on DigComp used in our study may affect the internal validity, but on the other hand should favor the external validity. We believe the instrument will be better adopted by different stakeholders, understanding the decisions taken without having a psychometric background. In the development of the platform, we prioritized the concerns and expectations of the users by providing them support in the availability of career pathways or helping them to detect their skill gaps. Our goal was to achieve a balance with the validity of the test through the design of the assessment instrument.

\subsection{Digital Competence for Entrepreneurs}

Information and communication technology (ICT) have transformed the nature of a great variety of entrepreneurial processes and outcomes, e.g. making the operations of start-ups easier, mediating for new ventures' and entrepreneurial operations, and enabling new digital business models (Nambisan et al., 2018; Steininger, 2019). As a result, new competences emerge to harmonize the digital transition of entrepreneurship. The skill requirements can vary depending on the context in which it is carried out (Autor, 2015). In addition, according to the data provided by Global Entrepreneurship Monitor (2018) 43\% of the global population see good opportunities for starting a business within the next six months. Digital entrepreneur has been defined as an entrepreneur in which some or all the entrepreneurial business activities occur digitally instead of in more traditional formats. Digital entrepreneurs must deal with singular challenges, such as instantaneous responses from contenders and the ability to telework and pursue unique opportunities (Hull et al., 2007). Hair et al. (2012) stated that market orientation is more challenging to achieve for new digital businesses but on the other hand, they also have more information about their competitors and customers, which can be used to enter the market efficiently by providing a clear competitive advantage. The ability to efficiently use the latest technology is relevant in developing entrepreneurship attitude and intensifies the importance of developing digital competences instead of only training technical skills (Scuotto \& Morellato, 2013). Sahut et al. (2019) identified four major research streams in digital entrepreneurship: (1) Digital 
business model contributions to strategy literature, (2) digitalization of entrepreneurial processes, (3) digital platform contributions to strategy literature, and (4) digital entrepreneurial ecosystem literature. The factors and motivational aspects of successful entrepreneurs have been identified and categorized as personal characteristics, knowledge, technical skills, roles and attitudes (Bi et al., 2017; Dhaliwal \& Sahay, 2020; Millán et al., 2019; Sussan \& Acs, 2017; Yunis et al., 2018). Oggero et al. (2019) found that individuals with digital skills are more likely to be entrepreneurs, and the effect is bigger for men. Despite this, insufficient effort has been made on analyzing the importance of digital technologies in shaping entrepreneurial opportunities, decisions, actions, and outcomes (Nambisan, 2017). Other contributions to the digital entrepreneur research have been focused on investigating the adoption, utilization and implications of the great advances in digital technology, such as mobile applications or digital technology platforms (Beliaeva et al., 2019; Durkin et al., 2013; Evans \& Schmalensee, 2016; Hayter et al., 2017; McIntyre \& Srinivasan, 2017; Nambisan et al., 2018; Olsson \& Bernhard, 2020; Srinivasan \& Venkatraman, 2018).

Even more, the literature on digital entrepreneurship lacks studies focused on the development of the entrepreneurial capacity. Specifically, studies focused on analyzing in depth which digital competences are essential for anyone interesting in becoming an entrepreneur regardless of the activity field. Sussan and Acs (2017) contextualized entrepreneurship in the digital age by integrating two well established concepts: The digital ecosystem and the entrepreneurial ecosystem. They provided a theoretical framework comprised of four concepts: (1) Digital infrastructure governance, (2) digital user citizenship, (3) digital entrepreneurship, and (4) digital marketplace. The digital user citizenship concept is important to stimulate policy makers in education to re-think what digital skillsets need to be promoted in order to link skills to entrepreneurship in the digital economy. Unfortunately, they did not discuss in-depth the digital skills that are necessary. The development of the entrepreneurial capacity of European citizens and organizations is one of the key policy objectives for the EU. The European Commission identified the sense of initiative and entrepreneurship as one of the 8 key competences necessary for a knowledge-based society. and develperd EntreComp: The Entrepreneurship Competence Framework. This framework identifies which elements are required to become an entrepreneur and establishes a common reference (Bacigalupo et al., 2016). According to the literature review and the examples identified by McCallum et al. (2018), there are not any examples of cases directly dealing with the definition and assessment of digital competences needed by entrepreneurs regardless of the activity field. The same happens in the 'Pathways for Employ' project, where only 3 out of the 70 cases included links between EntreComp and DigComp in some way. ENTRECOM4ALL (n.d.) linked entrepreneurial skills with relevant digital skills, although the self-assessment tool only identifies and assess the level of their entrepreneurial skills. REACT (n.d.) developed a practice mapping tool allowing to explore how each practice addresses the EntreComp and DigComp frameworks. Nevertheless, the definition and assessment of the digital competences needed to become an entrepreneur are not taken into consideration. WOW (n.d.) integrated entrepreneurial skills with the digital skills framework DigComp to demonstrate how the frameworks complement each other and how a digital conceptual reference model could be implemented in the field of entrepreneurship. Particularly, it was focused on a specific type of business (a crowdfunded business) and collective (disadvantaged women). Besides, the assessment of the digital competence was not addressed. Interestingly, this study is the only one that focused on the definition of the digital competence that people should need to become an entrepreneur and developed an assessment tool for evaluating the digital competence. It is aimed to citizenship interested in measuring their digital competence to develop into an entrepreneur. 


\subsection{Digital Competence for Teleworkers}

Today's knowledge work is supported by the Internet and can be carried out from almost any location and at any time. The independence of place has transformed the role of technology in the work environment, presenting new opportunities and challenges. Due to the displacement in labor market from manufacturing and construction to servicebased business, teleworking has globally been accepted by companies. These 'teleworkers' (also known as 'remote workers') can work independently or as part of a team in a variety of virtual arrangements. 'Remote work' is a broad concept that describes the situations where the work is fully or partly carried out at an alternative worksite than the default place of work. 'Telework' is considered as a subcategory of remote work, where the work carried out remotely involves the use of personal electronic devices, such as computers, tablets or smartphones (Eurofound and the International Labour Office 2017). Furthermore, teleworkers apply: (a) new skill sets such as technical skills to operate in a fully remote workplace, (b) problem-solving skills in an ICT-enabled working environment, and (c) social skills required for non-face-to-face interaction. In our study, we considered teleworkers as remote workers, i.e., workers who use ICT (e.g. smartphones, tablets, laptops and desktop computers) and tools (e.g. meeting tools, messaging, collaborative tools, and VPNs). In 2019, around $11 \%$ of dependent employees and $35 \%$ of the self-employed workers were working from home at least some of the time. This represents a huge increase from less than $8 \%$ and $29 \%$ respectively in 2008 . Moreover, telework has suffered a large expansion since the COVID-19, where closures forced many workers to telework (Sostero et al., 2020). Concerning mobility, employee mobility can improve employee productivity leading to $30 \%$ better processes, $23 \%$ more productivity, and 100\% more satisfied employees (Newman, 2016). Teleworking is an increasingly option among workers worldwide with positive effects such as a reduction in commuting time, greater working time autonomy leading to more flexibility in terms of working time organization, better overall work-life balance, and higher productivity. On the other hand, companies save money while allowing workers the freedom to create their own schedules and work from wherever they please (de Macêdo et al., 2020; Eurofound and the International Labour Office 2017).

Telework is not simply a new way of working. It establishes a new organizational form with new types of tasks, more complicated problems, and different management responsibilities (Mahler, 2012). Nevertheless, remote working is in general advantageous to employers and employees and the disconnection of work from place is undeniably part of the changing nature of work in the twenty-first century (Felstead \& Henseke, 2017). The main impediment to telework is the physical handling tasks that require a job to be carried out only at specific locations. Sostero et al. (2020) developed an index of technical teleworkability, based on an existing conceptual framework and taxonomy of tasks for occupational analysis created by Eurofound (2016) and using with data form European occupational surveys. Dingel and Neiman (2020) followed a similar approach to develop the work-from-home measure using surveys from O*NET and found that 37 percent of jobs in the United States can be performed entirely at home. They classified the feasibility of working at home for all occupations based on the physical and social factors that influence the nature of work, and the general types of job behaviors occurring on multiple jobs.

The digitalization of work imposed by telework has underlined the importance for employees to improve their digital competence and how existing gaps can affect their 
performance (Zamfir \& Aldea, 2020). Previous studies suggested that training on equipment set-up, connectivity, use at remote locations, and troubleshooting would be essential despite training was identified as simple difficulty compared to other IT issues (Dingel \& Neiman, 2020; Garrett \& Danziger, 2007; Haddon \& Brynin, 2005; Harmer \& Pauleen, 2012; Sostero et al., 2020; Vargas-Llave et al., 2020). Vargas-Llave et al. (2020) stated that digital competences are not only crucial for accessing work, but also for self-promotion and building an online reputation to guarantee employment opportunities and expand career prospects. In the international comparison of frameworks of twenty-first century skills carried out by Voogt and Roblin (2012), they identified retrieving and processing digital information, and communicating through digital devices as two essential components of the ICT competence. Moreover, Aesaert et al. (2014) identified retrieving and processing digital information; and communicating in a safe, sensible and appropriate way as two present topics in the national ICT curricula. As far as we know, no previous research has addressed or discussed the in-depth digital skills that are essential for anyone interesting in working remotely. Considering the wide spectrum of telework types and the nature of their working conditions where these competences are critical, we decided to select this profile and work with competences that are essential for most of the twenty-first century skills frameworks and national ICT curricula.

\section{Method}

In our study, we followed a quantitative and qualitative methodology that involved different input sources (expert consultation, questionnaires, and test results) for the design, development and validation of the assessment tool presented here. The qualitative methodology played a key role in validity checking. We gathered many valuable comments and suggestions in the exchange of feedback and online surveys that complemented the statistical analysis. The development of the assessing tool started with an initial design that was tested and refined at the same time we prepared the item bank for each test. The outcome of this process is a tool that addresses DigComp competence levels 1 to 6, which are the most widely needed digital competence levels for most European citizens and digital profiles. The features of our tool allow assessing digital competence by its 3 components, i.e. knowledge, skills and attitude, for each of the 5 DigComp areas, and that provides participants with a picture of their proficiency levels. The assessing tests were designed following a performance-based approach and we incorporated different types of items such as knowledge-based questions and practical exercises (real or simulated).

The final version of our tool provided an assessment and accreditation platform where digital profiles could be incorporated, and users could assess and validate their digital competence according to the required levels suggested by the experts. The target population included 16-65-year-old individuals, with different proficiency levels of digital competence, from different EU Member States. The selected countries represented countries with different percentage of skilled population in the society.

Our pragmatic approach taking DigComp as a reference was based on an iterative process of consultations with experts and end-users. In the process of validation, we sought to obtain relevant evidence for the proposed score interpretations and their relevance to the proposed use (Aesaert et al., 2014). Regarding reliability, we considered that results from the tests might be corroborated by information from other sources or erroneous results 
could be easily rectified. Therefore, scores with modest reliability might be accepted considering our time and budget limitations. Finally, we examined some psychometric properties of the items. It should be noticed that this tool is not intended to measure the individuals' current digital competence with the aim of getting a certification or similar purposes. In that case, we should have followed a different approach delivering the tests in a controlled environment rather than self-administering them. Figure 1 shows all the steps involved in the development of our assessing tool. We will describe each one in the following subsections.

\subsection{Needs Analysis of Digital Profiles}

\subsubsection{Participants}

Most of the partners had a good national network of telecentres, e-facilitators and endusers that were engaged in the surveys. They analyzed digital competences needs of young students/professionals from entrepreneurship and teleworkers sectors, with the cooperation of teachers specialized in related training. Tecnalia Research \& Innovation contacted professional staff that usually are teleworkers, and Team Academy Euskadi, a learning and experimentation laboratory Studies Centre set up in 2004 created around the concept of innovating leadership and engaged with the creation of teams of entrepreneurs for young people. Additionally, The Institute of Entrepreneurship Development contacted with different actors involved in the environment that promotes entrepreneurship. Concerning the respondents' profile for the entrepreneur digital profile $(n=82), 39 \%$ were trainers, teachers or e-facilitators, $19 \%$ were project managers or project coordinators, $16 \%$ were entrepreneurs or SMEs' directors or owners, and the rest included employees in SMEs,

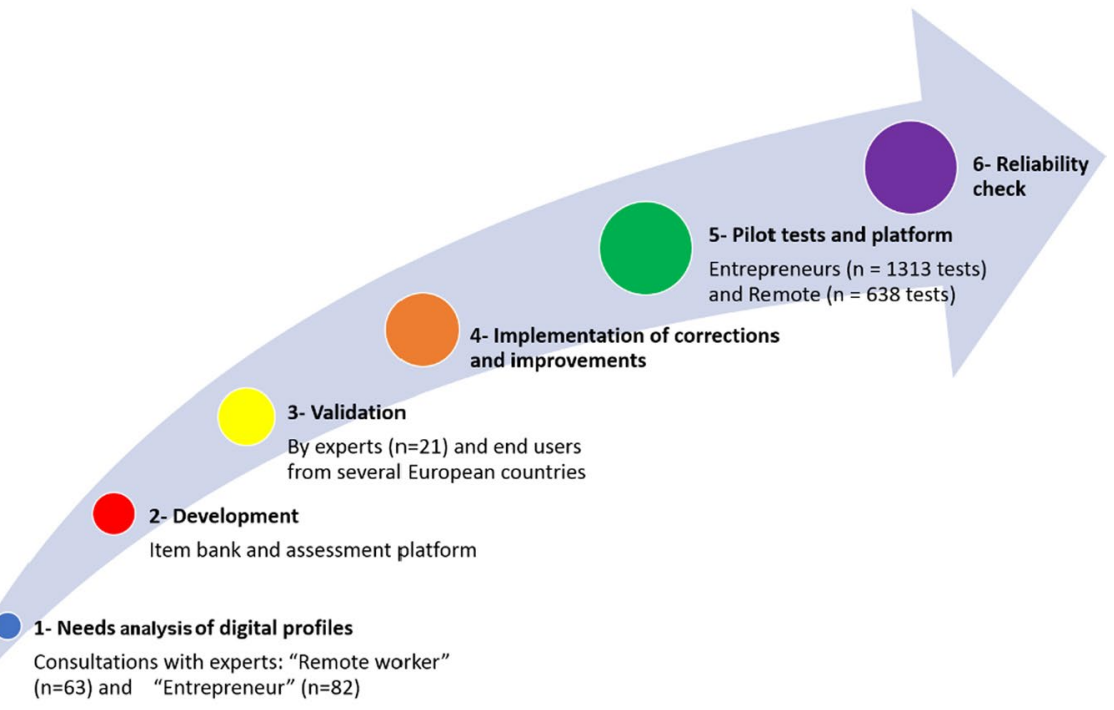

Fig. 1 Methodology followed in the development of the test 
consultants and others. And for the teleworker digital profile $(n=63): 26 \%$ project managers or project coordinators, $18 \%$ teleworkers, $15 \%$ IT freelance workers, $13 \%$ trainers, teachers or e-facilitators, and other less frequent professions are researchers $11.3 \%$ and consultants $8.1 \%$. Respondents were $55 \%$ male and $45 \%$ female. $59 \%$ were between 35 and 55 years old and 33\% between 25 and 34 years old. Respondents were from 15 different European countries, 52\% from Spain, 19\% from Latvia, 13\% from Greece and small shares from other countries.

\subsubsection{Materials}

For the needs analysis of both profiles we used online surveys (see Online_resource_1 in Appendix A). DigComp was considered for the elaboration of the survey questions, and additionally the EntreComp framework for the entrepreneur profile.

\subsubsection{Design}

The aim of this study was to understand which digital competences were needed by anyone who would like to work remotely or become an entrepreneur regardless of the activity field. Additionally, we asked participants to fill some information about their occupation/profile, country, gender and age. In the first part of the questionnaire we introduced the 21 digital competences according to DigComp and asked them to evaluate how relevant they considered each digital competence was ( 1 was the lowest relevance and 5 the highest) and the level needed for a good performance in entrepreneurship or working remotely (1 was the lowest level and 8 the highest). In the second part of the questionnaire of the entrepreneur, we included the 15 competences defined on EntreComp, and experts were asked to indicate which of those competences might be enabled through digital competences and with which of them. In the second part of the questionnaire of the virtual office worker, we asked them for those more general skills that teleworkers should possess (such as time-management, communication, work-life balance, etc.) and which digital competences would facilitate them (at least 5). In addition, for both digital profiles we asked participants for examples of activities performed with those competences in order to design the evaluation items based on authentic tasks performed by those profiles.

\subsubsection{Procedure}

A needs analysis of the digital profiles was conducted both at a national level (Spain, Latvia, Greece and Ireland) and at pan-European level, by Telecentre Europe. Information was gathered based on online surveys. Then, we calculated two important indicators for Relevance and Level: Average for Relevance and Level in each Digital Competence, and Percentage of total answers for each Digital Competence in Relevance and Level. To have a global view of the competences of both profiles, we examined the competences position attending the Relevance Average and Level Average. This information showed the importance of each competence. Finally, we used the Relevance Average to categorize the competences for both profiles. These results provided as work basis to define both digital profiles, to create an assessment syllabus and to orientate the implementation of the evaluation modules. 


\section{Results}

In the needs analysis of the digital profiles carried out by experts, for each digital profile, we obtained a table showing the Level Average and the Relevance Average for each digital competence (see Online_resource_2.png and Online_resource_3.png in Appendix A). Then, we obtained a graph showing the competences position considering the Relevance Average and Level Average (see Online_resource_4 and Online_resource_5 in Appendix A) (Fig. 2).

Essential competences were the most important competences (First group), and therefore we considered a high-level competence for this group according to survey results. Consequently, essential competences also had associated a high level in the average. Transversal competences were the competences with a medium relevance in the survey and we considered necessary in any task for this profile. The level for transversal competences would be less tough than the essential group of competences. Complementary competences were other group that improved the entrepreneur profile, but they were not essential: This group of competences had medium value in Relevance and Level. Moreover, we found that the fourth group contained competences with low relevance, and we proposed to exclude them. Regarding the proficiency level, we considered the percentage of answers which appear in the resume table. We defined the following criteria: Essential competences were defined by the thirty-five percentiles. Therefore, sixtyfive per cent of respondents believed that this level was the minimum required to each competence. For example, in the first competence of the entrepreneur profile at least $71 \%$ of people surveyed thought that the minimum level required was six. Transversal and Complementary competences followed the same criteria, but we chose a smaller percentile, twenty-five. Then, the final assessment syllabi were developed, presenting the content to be covered for each competence area and the cognitive levels based on DigComp (see Online_resource_6.jpg and Online_resource_7.jpg in Appendix A).

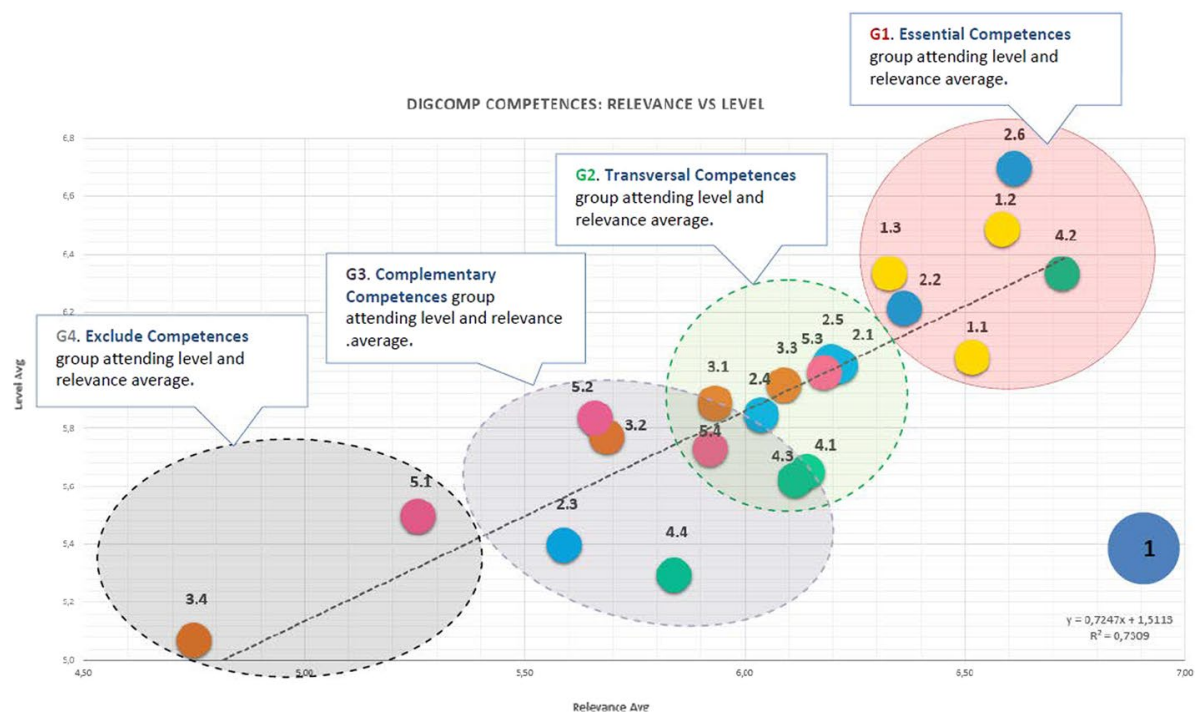

Fig. 2 Example of graph representing the Relevance average and Level average (entrepreneur) 


\subsection{Development}

\subsubsection{Participants}

The development was carried out by a multidisciplinary team of 21 professionals consisting of different partners of the project consortium. 33\% were researchers or technicians, $43 \%$ were project managers or project coordinators, and 23\% were SMEs' directors or owners. $48 \%$ were male and $52 \%$ female. Professionals were from 5 different European countries, 33\% from Spain, 10\% from Latvia, 19\% from Greece and 14\% from Belgium. Furthermore, $43 \%$ belonged to networks of digital competence centres.

\subsubsection{Materials}

The items of the tests were designed in storytelling terms and contextualized according to real situations that both profiles should face in a real context. We used a list of scenarios for each profile where digital competences were facilitators. This list was created based on the desktop research carried out in the previous step, the expertise of the partners and experts consulted. Due to the limitations of the project in terms of budget and time, we decided to choose a representative list of scenarios (see Online_resource_8.pdf in Appendix A).

\subsubsection{Design}

We designed the tests to evaluate the three components of the digital competence (knowledge, skills and attitude) based on a performance-based assessment.

\subsubsection{Procedure}

Our approach was based on the DigComp framework, a multidimensional framework structured in five competence areas. The first three competence areas are rather linear while the last two are more transversal, i.e. these areas apply to any type of activity that is been carried out through digital means. Although each area has its own particularities, there are several forced cross-references to other areas. In fact, these overlapping points at competence level have been indicated in the DigComp framework. Considering the complexity of the issue, we decided to develop one test for each competence area and digital profile, i.e. for each of the 5 dimensions defined in the DigComp framework. So, we decided not to consider that the competence areas are not self-contained or exclusive, and so they can be interrelated. Otherwise, the methodology would have become more complicated, for example, calibrating the items, calculating the correlation of sub scores within the different areas, etc.

We created the tests for each competence area (Information and data literacy, Communication and collaboration, Digital content creation, Safety and Problem solving) and digital profile (entrepreneur and teleworker), i.e. 10 tests in total. If a digital competence or proficiency level was not required for a profile, the corresponding items were not included in the test. We developed the item bank in 5 languages: English, Spanish, Basque, Greek and Latvian, since we did not want to add additional difficulty to use a language that some users did not handle well at all. Specifically, we developed 3 
different assessment items: knowledge, skill and attitude. All of them were dichotomous items except the attitudinal question, that we included a Likert scale of 5 points with several statements.

For the knowledge items, we created one for each level according to the DigComp 2.1 levels: foundation ( 1 and 2 ), intermediate ( 3 and 4) and advanced (5 and 6). They were mainly designed using multiple choice questions. Additionally, some of them were context-dependent items, i.e. they included a scenario, table or visual material that participants had to examine for responding the item. This format is very useful for measuring complex skills such as critical thinking (Haladyna et al., 2002); Furthermore, we followed the multiple-choice item-writing guidelines provided by Haladyna et al. (2002) to ensure enough validity evidence supporting the use of this type of items;

The skill items were focused on higher order skills, involving judgment and decision making. We developed two different types of items: (1) Simulations, based on interactive images and (2) Practical tasks, where participants must interact with the workstation. In simulations, the area of the clicks is automatically evaluated before deciding whether a new step should be shown or not. The simulations were based on the most extended and used programs. In practical tasks, participants have to carry out a task and upload the results to the platform. We developed this type of items using libraries such as Apache POI to automatically evaluate the results by the platform (Fig. 3).

Regarding the attitudinal questions, we tried to align the statements with the rest of the items in the same competence. We were aware that these scales should be validated to infer valid conclusions. Therefore, we decided to include them to make users aware that this component of the digital competence is of vital importance, but the results were not used for calculating the scores.

Finally, we developed some functionalities required for the accreditation web tool such as the registration of users, the repository of digital profiles, the personal digital profile, the history of tests taken, and finally, a functionality for comparing the levels achieved per digital competence with the levels recommended for the competence profiles. The development was based on open source software: Java Platform Enterprise Edition (J2EE), Struts framework, iBATIS and MySQL.

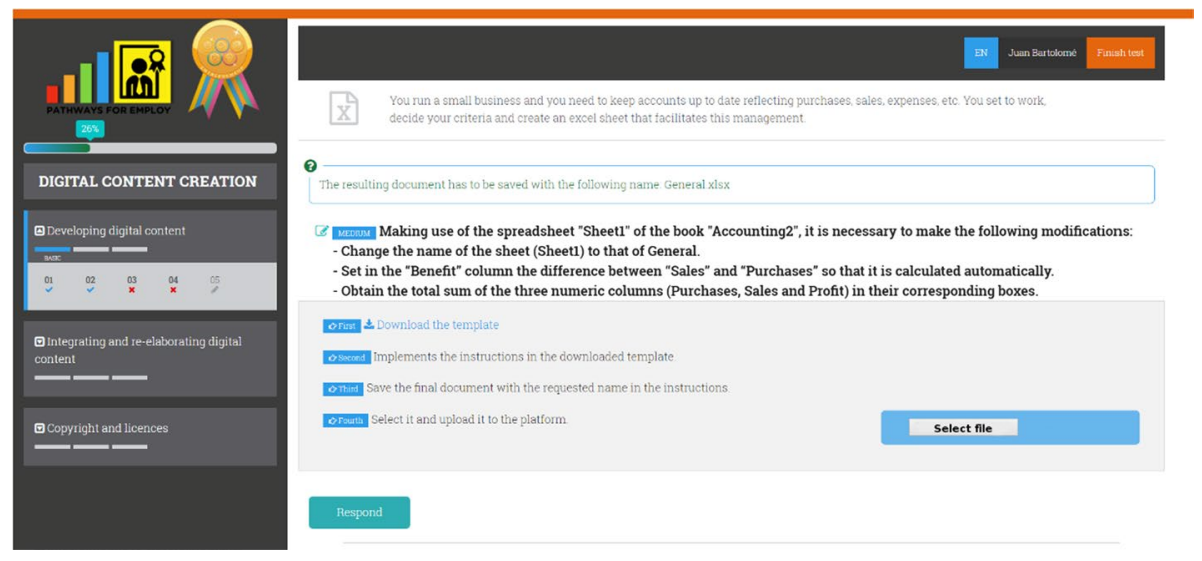

Fig. 3 Example of an item which requires interaction with the workstation 


\subsubsection{Results}

We developed the item bank and designed up to 20 items for each digital competence and integrated them into the online assessment and accreditation web tool. After developing and testing 204 knowledge items, 120 were selected and remained active. The same happened with the initial 88 skills items (simulations and practical exercises) where 34 were selected and remained active. The version of the item bank used was released and ready for the next step available on http://pathwaysforemploy.eu/. The initial item bank can be examined in Online_resource_9 in Appendix A.

\subsection{Validation and refinement}

\subsubsection{Participants}

In this step, we gathered information from 21 experts ( 9 males, 9 females and 3 other). Regarding their countries, 3 experts were from Latvia, 3 from Greece, 3 from Ireland, 9 from Spain, and 3 from the international network of All Digital. At least 3 digital skills trainers, teachers, researchers or employment experts were selected per partner, based on these criteria: Experience in digital competences; experience with assessment tools; English fluency; and general understanding about the entrepreneurs and teleworker profiles and tasks. Each partner carried out the selection and validation of its experts independently, according to the common criteria established.

\subsubsection{Materials}

The experts took the tests available on the platform and provided their feedback in 2 formats: Filling an online survey (see Online_resource_10 in Appendix A) and providing more detailed comments of specific issues by email. Additionally, we gathered additional recommendations and feedback made by the experts during this phase based on dialogues with respondents during test-taking or information collected through the free text entry fields of the surveys, categorizing them in five main categories: Language, Technical aspects, Content, Structure and Design.

\subsubsection{Design}

Experts chose one digital profile, took the 5 tests and for each test provided their degree of satisfaction with: the matching of the content of the questions, and the knowledge, skills and attitudes for that competence area; The adequacy of the evaluation criteria and the difficulty ranges; The quality of the information provided at the end of the test; the overall satisfaction with the assessment module; and finally, the overall satisfaction with the assessment platform.

\subsubsection{Procedure}

The expert piloting step took place from April to May (2018) in 5 countries (Latvia, Belgium, Spain, Ireland and Greece), where the online platform, the digital profiles, and the assessment tool were tested in English. A key part of gathering validity evidence was to analyze the internal test structure. For that, we relied on two fundamental pillars: (1) Carrying out 
our implementation based on the DigComp framework, applying its structure of competence areas and competences; and (2) carrying out a validation based on a panel of experts using a top-down design approach and exhaustively reviewing the bibliographic sources, as well as similar instruments already existing (Sireci \& Faulkner-Bond, 2014). We analyzed the relationship between the content of the tests and the construct it was intended to measure. We paid special attention to the wording, the format of the items, the questions, the levels and the tasks included. Each expert checked the 5 tests for one of the digital profiles selected: Teleworker $(n=11)$ and Entrepreneur $(n=10)$. Instructions were provided in face to face meetings explaining their role and tasks. Besides, all the items had a numerical identification that was used by the experts to reference a specific item if they had found it too difficult, hard to understand or included technical or typographical errors.

As a result, a further review of the item bank was carried out based on the comments and suggestions received by the experts. Initially there were 120 knowledge items and 44 skill items in the item bank. We adopted the following criteria for choosing the final items: belong to at least one scenario; be as short and simple as possible; and finally, address the digital competence selected, the specific competence element (knowledge, skills and attitudes) and the proficiency level (Foundation, Intermediate, Advanced); A key additional constraint considered for choosing the number of items in a test, was the time required for completing a test (10 min), in order to minimize the probability of users dropping out too early, leaving it incomplete. This step of improving and selecting the final items was led by Tecnalia on the basis of the information gathered in the previous step and subsequently validated by the other partners. As a result, an improved version of the platform and the tests were ready for the next step, available on http://pathwaysforemploy.eu/.

\subsubsection{Results}

In this step the validation was carried out by 21 experts. $71.4 \%$ of the respondents evaluated their satisfaction with the platform positively as shown in Table 1, and some aspects were identified to be improved for the next phase.

Experts mostly agreed (from $66.6 \%$ in digital content creation module to $80.9 \%$ in Information and data literacy module) that the content of the questions reflected the knowledge, skills and attitudes of the competence, as shown in Tables 2 and 3.

Referring to the content of test questions, experts evaluated if the assessment items were well written, well contextualized and easy to understand. Experts' opinion highlighted to improve the questions translation and formulation. Regarding the difficulty and adequateness of the test criteria, experts' opinion differentiated from module to module while the majority thought the criteria were adequate, as shown in Table 4.

Even more, experts replied positively about the information provided at the end of the test, as shown in Table 5. A significant part of respondents answered neutrally which pointed out that continuity should be accented more in future deployment.

Additionally, we analyzed the relationship between the overall satisfaction with the assessment platform, the satisfaction with the tests of each competence area

Table 1 Overall satisfaction with the assessment platform

\begin{tabular}{lllllll}
\hline $1($ not good at all $)$ & 2 & 3 & 4 & 5 & 6 (excellent) & Analysis \\
\hline $0.0 \%$ & $9.5 \%$ & $19.0 \%$ & $28.6 \%$ & $33.3 \%$ & $9.5 \%$ & M: 4.14 SD: 1.12 \\
\hline
\end{tabular}


Table 2 Overall satisfaction with the assessment modules

\begin{tabular}{|c|c|c|c|c|c|c|c|}
\hline Module & 1 (not good at all) & 2 & 3 & 4 & 5 & 6 (excellent) & Analysis \\
\hline $\begin{array}{l}\text { Area 1: information and data } \\
\text { literacy }\end{array}$ & $0.0 \%$ & $9.5 \%$ & $23.8 \%$ & $23.8 \%$ & $38.1 \%$ & $4.8 \%$ & $\begin{array}{l}\text { M: } 4.05 \\
\text { SD: } 1.09\end{array}$ \\
\hline $\begin{array}{l}\text { Area 2: communication and } \\
\text { collaboration }\end{array}$ & $0.0 \%$ & $9.5 \%$ & $9.5 \%$ & $33.3 \%$ & $38.1 \%$ & $9.5 \%$ & $\begin{array}{l}\text { M: } 4.29 \\
\text { SD: } 1.08\end{array}$ \\
\hline Area 3: digital content creation & $9.5 \%$ & $9.5 \%$ & $9.5 \%$ & $23.8 \%$ & $42.9 \%$ & $4.8 \%$ & $\begin{array}{l}\text { M: } 3.95 \\
\text { SD: } 1.4\end{array}$ \\
\hline Area 4: safety & $0.0 \%$ & $9.5 \%$ & $9.5 \%$ & $28.6 \%$ & $42.9 \%$ & $9.5 \%$ & $\begin{array}{l}\text { M: } 4.33 \\
\text { SD: } 1.08\end{array}$ \\
\hline Area 5: problem solving & $0.0 \%$ & $4.8 \%$ & $9.5 \%$ & $28.6 \%$ & $38.1 \%$ & $19.0 \%$ & $\begin{array}{l}\text { M: } 4.57 \\
\text { SD: } 1.05\end{array}$ \\
\hline
\end{tabular}

and the digital profiles selected. For this purpose, we calculated the Pearson coefficient. Results show that there is not a significantly correlation with the digital profile selected. Furthermore, results show that overall satisfaction of the assessment platform correlate significantly with the satisfaction with the tests from the competence areas Area1: Information and data literacy $\mathrm{r}(21)=0.677, \mathrm{p}<0.01$, Area2: Communication and Collaboration $\mathrm{r}(21)=0.566, \mathrm{p}<0.01$, and Area5: Problem solving $\mathrm{r}(21)=0.615$, as shown in Table 6. The Pearson coefficients for all the variables can be examined in Online_resource_11 in Appendix A.

Recommendations and feedback gathered from experts were categorized in five main categories:

- Language: proof reading was necessary, and some questions needed to be reformulated in a simpler manner, maintaining a consistent terminology;

- Technical aspects: several improvements were suggested such as the simulations usage;

- Content: assessment items needed to be made more specific, clearer and better formulated. Furthermore, experts noted that some questions are easier to respond if you were more used to the program which appears in the simulation;

- Structure: we had to formulate the questions shorted and simpler. Besides, it was also mentioned to restructure the feedback page to make it more understandable and send an e-mail with results at the end of the test;

- Design: we had to make the contextual statements with explanatory information clearer and more visual as they were often missed, also sometimes they could be weakly related to the context of question.

As a result of the refinement carried out in the previous step, weak items were removed or modified, and we decided to include the following configuration for each digital competence: 3 knowledge items (1 foundation, 1 intermediate and 1 advanced), 1 skills question and 1 attitudinal question with several statements. Consequently, 80 items (knowledge and skills) were available for each digital profile in addition to the attitude items (see Online_resource_9 in Appendix A). This decision reduced the duration of the tests according to the time constraint taken into account and enabled the implementation of the next step. 


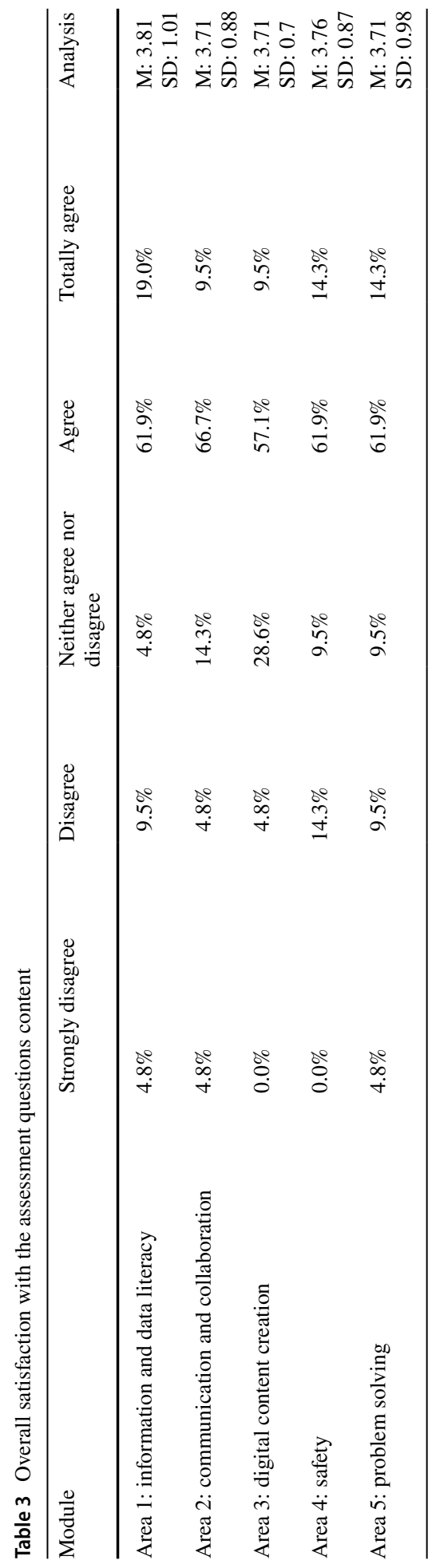




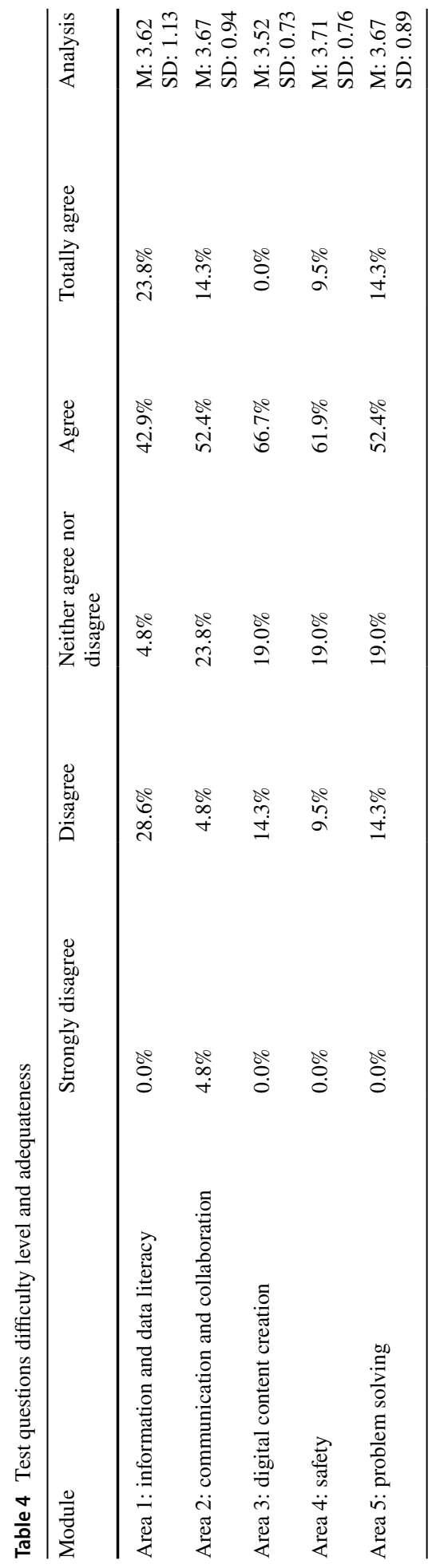




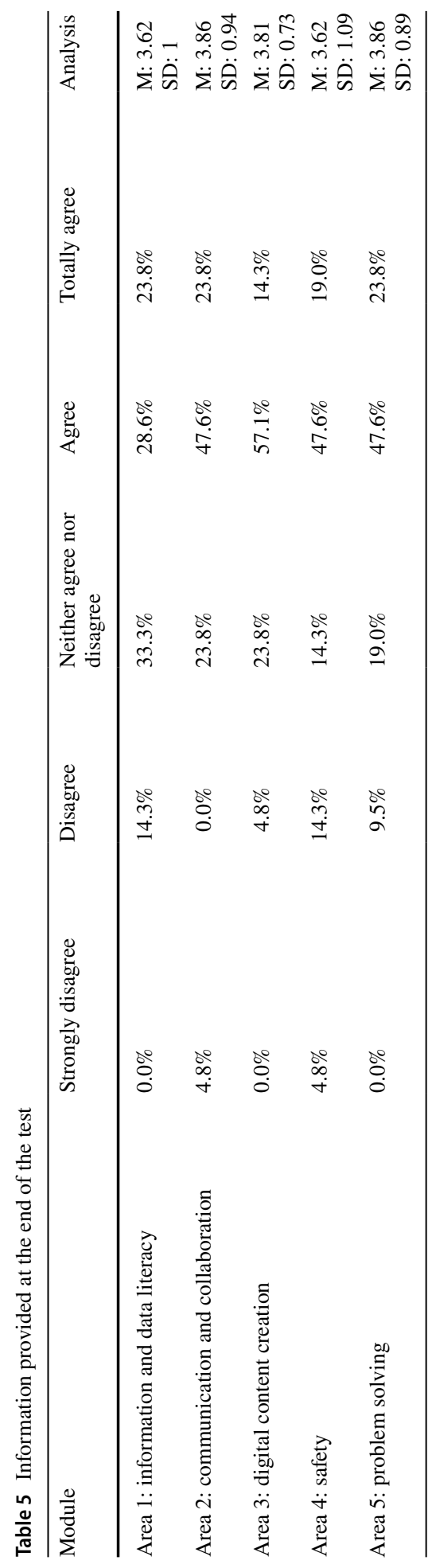


Table 6 Relationship between the satisfaction with the tests of the competence areas, overall satisfaction of the assessment modules and the digital profiles selected. Pearsons Correlations $(* \mathrm{p}<0.05$ (bilateral); ** $\mathrm{p}<0.01$ (bilateral))

\begin{tabular}{clllllllll}
\hline & \multicolumn{3}{c}{$\begin{array}{l}\text { Digital } \\
\text { Profile }\end{array}$} & Area1 Sat & Area2 Sat & Area3 Sat & Area4 Sat & Area5 Sat & Overall Sat \\
\hline Digital & $\mathrm{r}(21)$ & 1 & $.440^{*}$ & .277 & .374 & .170 & .127 & .008 \\
Profile & & & & & & & & \\
& Sig & & .046 & .225 & .095 & .461 & .582 & .972 \\
Area1 Sat & $\mathrm{r}(21)$ & $.440^{*}$ & 1 & $.747^{* *}$ & $.625^{* *}$ & $.567^{* *}$ & $.617^{* *}$ & $.677^{* *}$ \\
& $\mathrm{Sig}$ & .046 & & .000 & .002 & .007 & .003 & .001 \\
Area2 Sat & $\mathrm{r}(21)$ & .277 & $.747^{* *}$ & 1 & $.872^{* *}$ & $.873^{* *}$ & $.902^{* *}$ & $.566^{* *}$ \\
& $\mathrm{Sig}$ & .225 & .000 & & .000 & .000 & .000 & .008 \\
Area3 Sat & $\mathrm{r}(21)$ & .374 & $.625^{* *}$ & $.872^{* *}$ & 1 & $.888^{* *}$ & $.857^{* *}$ & $.473^{*}$ \\
& $\mathrm{Sig}$ & .095 & .002 & .000 & & .000 & .000 & .031 \\
Area4 Sat & $\mathrm{r}(21)$ & .170 & $.567^{* *}$ & $.873^{* *}$ & $.888^{* *}$ & 1 & $.954^{* *}$ & $.537^{*}$ \\
& $\mathrm{Sig}$ & .461 & .007 & .000 & .000 & & .000 & .012 \\
Area5 Sat & $\mathrm{r}(21)$ & .127 & $.617^{* *}$ & $.902^{* *}$ & $.857^{* *}$ & $.954^{* *}$ & 1 & $.615^{* *}$ \\
& $\mathrm{Sig}$ & .582 & .003 & .000 & .000 & .000 & & .003 \\
Overall Sat & $\mathrm{r}(21)$ & .008 & $.677^{* *}$ & $.566^{* *}$ & $.473^{*}$ & $.537^{*}$ & $.615^{* *}$ & 1 \\
& $\mathrm{Sig}$ & .972 & .001 & .008 & .031 & .012 & .003 & \\
\hline
\end{tabular}

\subsection{Pilot tests and platform}

\subsubsection{Participants}

525 end-users participated in this step from 23 different countries, being Spain (72.53\%), Greece (13.18\%) and Latvia (6.5\%) the most present. Their details are shown in Table 7. We invited the participants of the pilot following 2 main strategies: (1) Controlled groups, normally taking place during digital skills of entrepreneurship related trainings; and (2) open calls for end-users. Furthermore, according to the results of the surveys, the participants were quite confident with their digital competence level: $39 \%$ advanced; $43 \%$ intermediate; $8 \%$ foundation; and $10 \%$ initial. After gathering the results from the participants, we reviewed the thresholds for each digital competence, because the proficiency levels are assigned considering competence level. For the intermediate level, we used the range within one standard deviation above and below the mean. This cluster corresponds to two thirds of the scores and represents two thirds of the participants. For the foundation and advance levels, we did something similar by subtracting or adding two standard deviations respectively. A maximum of 11 points could be scored in each competence.

Table 7 Information about the end-users

\begin{tabular}{|c|c|c|c|c|c|c|c|c|c|c|}
\hline \multicolumn{2}{|c|}{ Gender } & \multicolumn{3}{|c|}{ Employment status } & \multicolumn{3}{|l|}{ Age } & \multicolumn{3}{|c|}{ Education level } \\
\hline $\mathrm{F}$ & M & Employee & Unemployed & Self-employed & $16-24$ & $25-54$ & $\geq 55$ & High & Medium & Low \\
\hline $55.1 \%$ & $44.9 \%$ & $82.3 \%$ & $7.4 \%$ & $6.2 \%$ & $5.7 \%$ & $87.8 \%$ & $6.1 \%$ & $69.1 \%$ & $28.8 \%$ & $2.1 \%$ \\
\hline
\end{tabular}




\subsubsection{Materials}

The participants completed the tests on the assessment platform available on http://pathw aysforemploy.eu/. Furthermore, participants gave feedback based on online surveys delivered at the end of the piloting session. The surveys were localized into Latvian, Greek, Spanish, and English (see an example, Online_resource_12 in Appendix A).

\subsubsection{Design}

During the piloting sessions we gathered the following information during the registration the participants: gender, employment status, age range and educational level. Furthermore, from the tests performed we registered the responses for each item and automatically calculated the levels achieved per digital competence. Additionally, from the surveys we collected information on the main following aspects in order to evaluate and improve the platform: each modules and competence areas technical performance; overall satisfaction with the online assessment tool; content of the tool (evaluation of the corresponding levels); understandability of the test results; and satisfaction with the test design.

\subsubsection{Procedure}

This step was carried out between June (2018) and January (2019) with the aim of testing the online assessment platform. 525 end-users participated and 1951 tests were taken, representing both pathways: entrepreneurs $(n=1313)$ and teleworkers $(n=638)$. The languages of the piloting were English, Spanish, Latvian, Greek and Basque. Participants were invited to test all 5 competence areas for a specific profile or just some of them. Respondents could select one of the available languages before taking the tests. Results were saved automatically and updated the digital profile of the participant. Moreover, users could repeat the same test in to improve the level previously achieved. All the items were dichotomous and were pondered according to the following criteria for the knowledge questions (foundation 1point; intermediate 2 points; and advance 3 points) and 5 points for the skills question. The attitudinal questions were not graded. We decided to assign a bigger punctuation to the skills questions since we considered that they were more discriminating and require higher order skills to resolve them. The thresholds for each digital competence were defined based on the punctuation achieved: Initial level $(<9 \%)$; Foundation $(\geq 9 \% \mathrm{y}<36 \%)$; Intermediate $(\geq 37 \% \mathrm{y}<53 \%)$; and Advanced $(>54 \%)$. We agreed that this configuration fitted well with the different levels defined. Furthermore, participants gave feedback based on online surveys delivered at the end of the tests, entrepreneurs $(n=255)$ and teleworkers $(n=343)$, in several languages: 328 Spanish, 60 English, 80 Latvian, 108 Greek 108 and 24 Basque.

\subsubsection{Results}

Then we piloted the test and the platform with end-users. Regarding the respondent's overall satisfaction with the platform, $66 \%$ were "Very satisfied/ satisfied" which was considered as a good overall result, $9 \%$ were not satisfied and $25 \%$ were partly satisfied. Regarding the test results and the information received after passing the tests, $64 \%$ stated that the test results were understandable and $30 \%$ stated that the results were partly understandable. Only $6 \%$ replied that they had not understood the results. 
Respondents suggested adding the missing/low competence areas to the result report, not only the positive feedback. Even more, $49 \%$ of the respondents claimed that the test helped them to understand their digital competence gaps and level, and $31 \%$ answered partly. While $20 \%$ of respondents did not see that the tool helped them to this issue.

Regarding the results obtained by the participants, the general observation is that even inside each competence area the levels of test results for single competences might differ. It can be explained by the multidimensional character of the DigComp framework, particularly different technologies, different application areas (scenarios), different difficulty levels and different question types (attitude, knowledge, skills). Levels achieved for each competence area and digital profile can be examined in Online_resource_13. in Appendix A (Fig. 4).

Data analysis performed after the pilot suggests that the tests available on the assessment platform may be used to indicate the digital competence level of the participants as there are clusters of people who perform better or worse than average with statistical significance. Examining the results of the analysis performed for establishing the thresholds of the scores, we decided to modify their limits. An example for the Information and data literacy area can be examined in Tables 8 and 9. The complete analysis can be found in Online_resource_13 in Appendix A. It should be noted that in competences 3.1 and 4.3 the skill items were biased, and participants could not achieve fair results. Once we fixed the problems with these two items, we decided to keep the initial intervals for these two competences and wait for new results to be available for re-analysis.

\section{Problem solving}

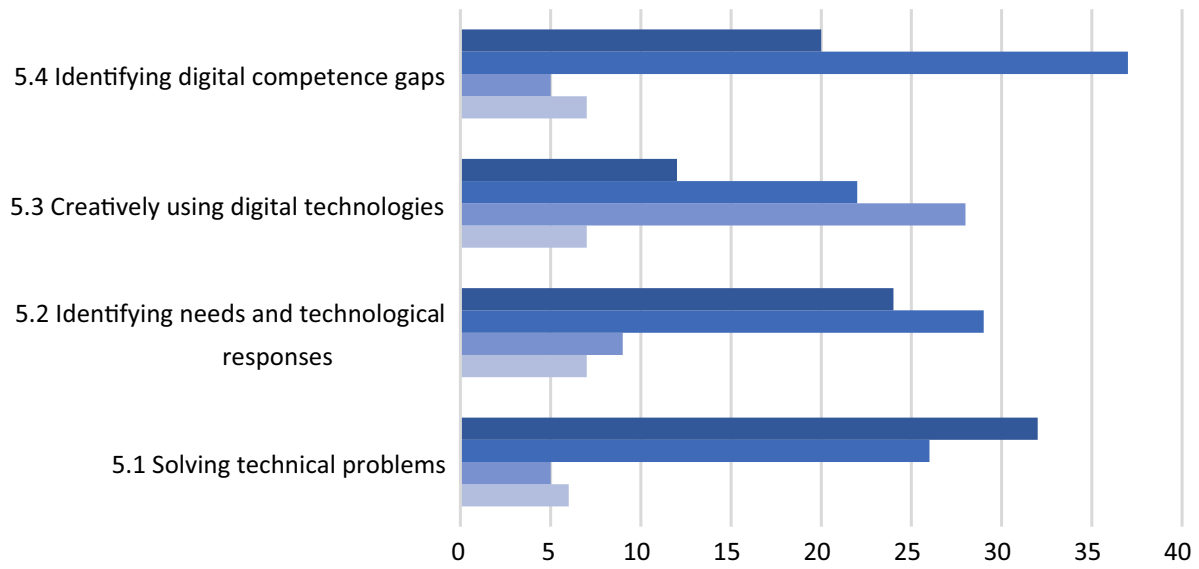

Advanced Intermediate $\quad$ Foundation Initial

Fig. 4 Example of results in the "Problem solving" competence area for the Entrepreneur digital profile 
Table 8 Information and data literacy area-statistical analysis of the scores

\begin{tabular}{llll}
\hline Competence & 1.1 & 1.2 & 1.3 \\
\hline Participants & 310 & 310 & 310 \\
M & 7.34 & 5.44 & 7.37 \\
SD & 3.28 & 3.10 & 3.70 \\
Limit 1 (M - 2*SD) & 0.77 & -0.07 & -0.03 \\
Limit 2 (M - 1*SD) & 4.06 & 2.33 & 3.66 \\
Limit 3 (M+1*SD) & 10.63 & 8.54 & 11.07 \\
Limit 4 (M+2*SD) & 13.99 & 11.65 & 14.77 \\
\hline
\end{tabular}

\begin{tabular}{lllll}
\hline Proficiency level & Initial Intervals & $\mathrm{r} 1.1$ & $\mathrm{r} 1.2$ & $\mathrm{r} 1.3$ \\
\hline Initial & $(0-1)$ & $(0-1)$ & 0 & 0 \\
Foundation & $(2-3)$ & $(2-3)$ & $(1-2)$ & $(1-3)$ \\
Intermediate & $(4-6)$ & $(4-10)$ & $(3-9)$ & $(4-10)$ \\
Advance & $(7-11)$ & 11 & $(10-11)$ & 11 \\
\hline
\end{tabular}

Table 9 Initial and reviewed scoring thresholds

\subsection{Reliability Check and Quality of Individual Item}

\subsubsection{Participants}

525 end-users participated in this step from 23 different countries, being Spain $(72.53 \%)$, Greece (13.18\%) and Latvia (6.5\%) the most present. Same participants as in the previous step. Their details are shown in Table 7. We invited the participants of the pilot following 2 main strategies: (1) Controlled groups, normally taking place during digital skills of entrepreneurship related trainings; and (2) open calls for end-users. Furthermore, according to the results of the surveys, the participants were quite confident with their digital competence level: $39 \%$ advanced; $43 \%$ intermediate; $8 \%$ foundation; and $10 \%$ initial.

\subsubsection{Materials}

Results from the participants who completed the tests on the assessment platform. Furthermore, we decided to choose only the results from the entrepreneur profile as a case of use, considering that this profile had the bigger amount of responses $(n=1313)$.

\subsubsection{Design}

We calculated some indicators for the overall reliability and quality of individual item. To check the internal consistency of a test based on Classical Test Theory we calculated the Cronbach's alpha. We examined the Means and Standard Deviation to display the distribution of items. Furthermore, we also calculated the Difficulty index and the Discrimination index. 


\subsubsection{Procedure}

First, we analyzed the reliability of the tests and performed an analysis of the results from the previous step $(n=1951)$ based on Classical Test Theory. One of the most common indicators to check the internal consistency of a test based on Classical Test Theory is Cronbach's alpha, since intercorrelations among test items are maximized when all items measure the same construct. It is widely believed to indirectly indicate the degree to which a set of items measures a single unidimensional latent construct. In addition, we decided to remove the tests from users whom did not respond at least $2 / 3$ of the test, supposing that they did not take the exam with real interest, leaving 994 tests. Beyond Cronbach's alpha, we calculated item statistics such es Means and Standard Deviation to display the distribution of items. Item statistics can indicate which items might decrease reliability and therefore, replacing or deleting them should be considered. We also calculated the Difficulty index and the Discrimination index. Item difficulty is the proportion of test takers who answered correctly out of the total number of test takers, i.e. is a measure of individual test question difficulty. The Discrimination index measures how discriminating items in a test are, i.e. how well an item can differentiate between candidates of different levels.

\subsubsection{Results}

We examined the reliability based on Classical Test Theory calculating Cronbach's alpha for each test, including other indicators such as Difficulty indexes, Discrimination indexes, Means and Standard Deviations (see details in Online_resource_14.pdf in Appendix A). About the reliability of test scores, a widely accepted intervals for describing internal consistency using Cronbach's alpha is as follows: $\geq 0.9$ excellent $; \geq 0.8$ and $<0.9$ good; $\geq 0.7$ and $<0.8$ acceptable; $\geq 0.6$ and $<0.7$ questionable; $\geq 0.5$ and $<0.6$ poor; $>0.5$ unacceptable. Before implementing the changes and the corrections two of them were already acceptable, as shown in Table 10.

We found that the questions identified as skills items showed better discriminators coefficients that knowledge-based questions. Besides, in some competences there were some items with difficulty levels harder or easier than expected. According to the international standards, the distribution of the results for the discrimination coefficients are: $<0$ negatively; $0-0.14$ poorly; $0.15-0.25$ regular; $0.26-0.35$ good; $>0.35$ excellent. From the results of the 5 tests, we identified different discriminating rates: 2 items discriminating negatively. S1 in the "Digital content creation" area had technical problems and was fixed. C7 in the "Problem solving area", was replaced because it was badly worded and was very difficult to understand. 9 items discriminating poorly of which only s6 in "Communication and collaboration" area and s3 in "Problem solving" area were skill items. Concretely, the problems were due to not clear steps in the simulations and needed to be redesigned again. Concerning the knowledge questions, they were reworded to improve the comprehension and we examined the available responses to detect options with low possibilities of being chosen. 15 items discriminated regularly, and all of them were knowledge questions. They were checked to improve the understanding of the questions and possible responses, replacing options with low possibilities of being selected. Finally, 20 and 21 items were categorized as good and excellent discriminators respectively. These items were maintained without implementing changes. Except 3 simulations that were modified, 6 were identified as good and 9 as excellent discriminators. According to the approach taken, we decided to 


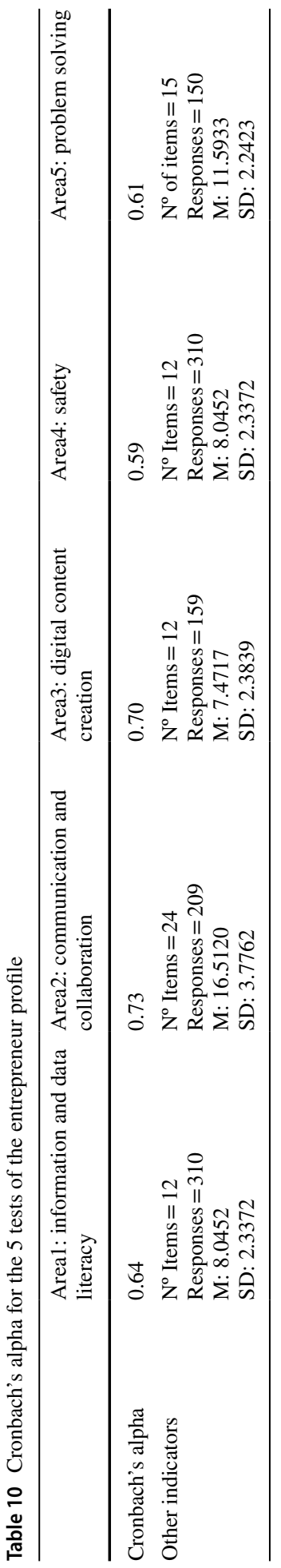


modify or replace the weak items instead of just eliminating them to improve the internal consistency, in order to keep the structure and understanding of the test.

\section{Discussion}

Nowadays, the need of defining and assessing digital competence has increased, but unfortunately most of the available instruments for the evaluation of digital competences do not meet the desired requirements or do not deal with all the components of the digital competence (Kluzer \& Priego, 2018; Law et al., 2018; Siddiq et al., 2016). DigComp has been applied for various pragmatic purposes in this pathway (Kluzer \& Priego, 2018). Pragmatic methods are usually created by a panel of experts using a top-down design approach, to produce a list of competences with their assessment syllabus. This approach is suitable for the purpose of curriculum design or developing diagnostic self-assessment tools. So, considering the purpose of our study, we decided to follow a similar approach. Furthermore, the reliability and validity of a performance-based test it is a big challenge, and even more when the test measures a complex construct such as digital competence (UNESCO Institute for Statistics, 2019). We also considered an alternative based on a psychometric approach, but to obtain valid conclusions from the results, we would have needed to guarantee some very difficult assumptions in the case of a performance-based assessment. Besides, we would have needed to follow a distinct and more complex methodology, with other requirements, such as, the need for a larger item bank, get more responses to calibrate the item bank, or to apply a multidimensional model. And therefore, we decided to evaluate each digital competence as an independent construct, without taking into account the overlapping points at competence level identified in the DigComp framework. With this approach, we prioritized the external validity of the assessment instrument, but required us to describe in detail all the steps and decisions taken in order to be better understood, accepted and used by a wider public, as Van Deursen et al. (2016) demanded. On the other hand, we were aware that this type of approaches tends to penalize the internal validity. A psychometric approach would improve the internal validity of the assessment but would reduce the external validity. As previously mentioned, it would be recommendable to elaborate a larger item bank. In fact, increasing the size of items in a test, is a commonly way for improving the reliability. As well, from the beginning we had clear that we could not expect obtaining a higher degree of reliability and precision due to the decisions taken, such as elaborating a short number of items per digital competence. Despite this limitation, we considered that the decisions derived from the results were not so critical as to seek a higher degree of precision and reliability.

We realized that the implementation of the methodology required quite complex skills of the people involved in its implementation, apart from experience working with digital competences it was necessary other complementary skills such as a deep understanding of the DigComp Framework, some experience in measuring digital skills, or writing skills for formulating the statements of the questions in the clearest possible way. We incorporated the DigComp framework in the definition of the competence profiles and later, on the design and development of the assessment modules. It provided us clear and well-defined criteria that was adapted according to our necessities in all the phases of the development. Besides, the credibility and reliability of the framework due to the EU origin and endorsement, contributed to the dissemination of the project. At the beginning, in the needs analysis carried out by experts, we used the framework descriptors which settle which 
knowledge, skills and attitudes which are required for each digital competence. One of the conclusions reached was that DigComp is hardly known in the professional word. Despite this fact, the adoption of DigComp contributed to create a common understanding to discuss about digital competence among those involved in the process. This contribution was essential for the evaluation and positive feedback received about the assessment modules, the content of the questions, their difficulty level and adequateness, and the information provided at the end of the tests. Besides, the DigComp framework is the most appropriate when talking about digital competence as a transversal component that is necessary for a wide variety of work profiles. Furthermore, experts who knew the DigComp framework had serious doubts concerning specific digital competences such as Creatively using digital technologies, Programming or Engaging in citizenship through digital technologies. This lack of clarity might be one of the reasons why the programming competence was not selected as required in either of the two chosen profiles. Other studies faced similar challenges taken DigComp as a reference through expert consultation as we did in this study. In the definition of digital profiles, BAIT (n.d.) defined the Administrative profile in order to be demanded for working in the public sector, Compass (n.d.), MuSA (n.d.) and SMARTIVEMAP (n.d.) defined several digital profiles such as: vocational education teachers, finance professionals, secretaries, ICT services, etc., and IKANOSTEST (n.d.) described several digital profiles for employability, including industry 4.0 job profiles. Even more, IKANOSTEST (n.d.) introduced the concept "sub-competence" to identify specific work tasks relevant for a specific digital competence, which need to be highlighted in the profile. A future line of work could be to apply this approach to enrich both profiles with more specific tasks.

We also used DigComp in the development of the item bank to identify the required content and to assign the levels of the items according to the descriptors. These descriptors have been defined using the Bloom's taxonomy, so we analyzed the statements of the items, identified the verbs used and propose a level. Once the assessment syllabus was specified, we developed and integrated the tests on the assessment and accreditation platform. Evaluation items in computer-based assessments can be diversified in terms of design and content. Specifically, we designed the tests with questions not based on specific applications or devices such as it was suggested by Law et al. (2018). At least we tried to ensure that the focus of the question was not on the tool itself. Moreover, the platform was designed to allow the incorporation of new digital profiles, and to enable the users to assess and validate their digital competence with the profiles selected identifying their gaps. Using the framework helped us to present the results in a way that was mostly understandable. Despite of the positive feedback provided by the participants, there is still margin for improvement. Besides, the quality of the assessment in terms of validity, reliability, and efficiency, is not affected by the inclusion of feedback (Shute \& Rahimi, 2017). If we want to reach a broader view not only centered on objectively measuring skills, we could improve the presentation of the results at the end of the tests. Based on the criteria provided by the framework, we could enrich the results by adding what requires for moving on to the next level in the digital competences that the individual did not complete for a specific digital profile. If we outline the expected learning outcomes by mentioning DigComp and training offers available are based on the same criteria, it would be a clear added value. Besides, the second version of the framework provided a wider and more detailed range of proficiency levels, very helpful for the development of more specific learning materials, the design of tools for assessing the digital competence and career guidance.

Additionally, considering that the construct definition understands digital competence as reliant on ICT-specific knowledge as well as comprehension and problem-solving 
skills, we paid special attention to the linguistic complexity of the test items following the experts' recommendations. In tasks that required a deep observation of reality and demanded efforts on reading comprehension, the linguistic complexity is a key factor. Plath and Leiss (2018) suggested that increasing the linguistic complexity of the tasks reduced the response success rate and Abedi and Lord (2001) confirmed that linguistic modifications of test items resulted in significant differences, obtaining slightly higher results. Thus, we initially created them in English and later, we translated them to the rest of languages, to avoid unnecessary linguistic complexity which could result in construct-irrelevant variance and could affect the validity of the tests (Abedi, 2006).

From the classical test analysis and reliability check, we saw that questions identified as skills items shown better discriminators coefficients that knowledge-based questions. Unfortunately, the development of this kind of items (simulations or real tasks) require more time and effort. In the quality analysis of the items, we found that we did not manage to align the levels correctly in several competences (e.g., a question at the intermediate level seemed harder than the advanced level). For adjusting the level of difficulty in an heterogenous items bank, Engelhardt et al. (2017) stated how changes of the item characteristics can influence the item difficulty without modifying the represented construct (e.g., we could decrease the number of attempts allowed in a simulation to increase its level of difficulty). Furthermore, if we had a sufficiently large item bank, we could select the items with the most suitable discrimination coefficients according to the required levels. An interesting approach might be the application of semantic analysis techniques during the development of the evaluation items, to suggest which levels should be applied analyzing the verbs used in the statements according to the Bloom's Taxonomy (e.g., "Identify" should be associated with low levels and "evaluate" with higher levels). Besides, under Classical Test Theory (CTT) results need to be interpreted in the context of the person's characteristics and test characteristics (e.g., the person's ability will appear low if the test questions are difficult). This may explain why the level of most of the tests seemed to be easy, considering that most participants declared a high level of digital competence.

This paper contributes to the definition and assessment of digital competence of digital profiles providing empirical results. We have followed a pragmatic approach based on DigComp which makes use of a common language and criteria that facilitated the development of a tool as the presented in the study. We hope that the explanations about the steps and decisions taken could serve as inspiration to stakeholders interested in carrying out their own implementations, following a similar approach.

Supplementary Information The online version contains supplementary material available at https://doi. org/10.1007/s10758-021-09516-3.

Acknowledgements This study has been partially funded by the European Commission (ERASMUS+ 2016-1-ES01-KA204-024983). We also would like to thank the P4E project consortium (Tecnalia Research \& Innovation (SP), The Institute of Entrepreneurship Development (GR), All Digital (BE), FIT-The ICT Pipeline (IE), KZ Gunea (SP), Consorcio Fernando de Los Ríos (SP) and SIA Data Media Group (LV)) and our collaborators and experts who participated during the piloting phase in the assessments, for their work and support.

\section{Declarations}

Conflict of interest On behalf of all authors, the corresponding author states that there is no conflict of interest. 


\section{References}

Abedi, J. (2006). Language issues in item development. Handbook of test development, 377-398.

Abedi, J., \& Lord, C. (2001). The language factor in mathematics tests. Applied Measurement in Education, 14(3), 219-234

Aesaert, K., Van Nijlen, D., Vanderlinde, R., \& van Braak, J. (2014). Direct measures of digital information processing and communication skills in primary education: Using item response theory for the development and validation of an ICT competence scale. Computers \& Education, 76, 168-181

Aesaert, K., Voogt, J., Kuiper, E., \& van Braak, J. (2017). Accuracy and bias of ICT self-efficacy: An empirical study into students' over-and underestimation of their ICT competences. Computers in Human Behavior, 75, 92-102

Ala-Mutka, K. (2011). Mapping digital competence: Towards a conceptual understanding. Sevilla: Institute for Prospective Technological Studies, 7-60.

American Educational Research Association, American Psychological Association, National Council on Measurement in Education, Joint Committee on Standards for Educational, \& Psychological Testing (US). (1999). Standards for educational and psychological testing. Amer Educational Research Assn.

Autor, D. H. (2015). Why are there still so many jobs? The history and future of workplace automation. Journal of Economic Perspectives, 29(3), 3-30

Bacigalupo, M., Kampylis, P., Punie, Y., \& Van den Brande, G. (2016). EntreComp: The entrepreneurship competence framework. Luxembourg: Publication Office of the European Union, 10, 593884

BAIT (n.d.). Evaluation and certification system of digital competences in the Basque Country. Retrieved October 28, 2019, from http://www.bait.eus.

Baruch, A. F., \& Erstad, O. (2018). Upbringing in a digital world: Opportunities and possibilities. Technology, Knowledge and Learning, 23(3), 377-390

Beliaeva, T., Ferasso, M., Kraus, S., \& Damke, E. J. (2019). Dynamics of digital entrepreneurship and the innovation ecosystem. International Journal of Entrepreneurial Behavior \& Research.

Bennett, R. E., \& Bejar, I. I. (1998). Validity and automad scoring: It's not only the scoring. Educational Measurement: Issues and Practice, 17(4), 9-17

Bi, R., Davison, R. M., \& Smyrnios, K. X. (2017). E-business and fast growth SMEs. Small Business Economics, 48(3), 559-576

Binkley, M., Erstad, O., Herman, J., Raizen, S., Ripley, M., Miller-Ricci, M., \& Rumble, M. (2012). Defining twenty-first century skills. In Assessment and teaching of 21st century skills (pp. 17-66). Springer, Dordrecht.

Carretero, S., Vuorikari, R., \& Punie, Y. (2017). DigComp 2.1: The Digital Competence Framework for Citizens. Publications Office of the European Union.

Cascio, W. F., \& Montealegre, R. (2016). How technology is changing work and organizations. Annual Review of Organizational Psychology and Organizational Behavior, 3, 349-375

Cedefop. (2015). European guidelines for validating non-formal and informal learning. Luxembourg: Publications Office. Cedefop reference series; No 104. https://doi.org/10.2801/008370

Colbert, A., Yee, N., \& George, G. (2016). The digital workforce and the workplace of the future.

Compass (n.d.). Up-skilling online training course for young unemployed people. Retrieved October 28, 2019, from https://www.compassdigitalskills.eu/.

de Macêdo, T. A. M., Cabral, E. L. D. S., Silva Castro, W. R., de Souza Junior, C. C., da Costa Junior, J. F., Pedrosa, F. M., \& Másculo, F. S. (2020). Ergonomics and telework: A systematic review. Work, (Preprint), 1-11.

Dhaliwal, A., \& Sahay, A. (2020). Factors influencing the success of women entrepreneurs in Emerging Markets: A Study of Indian women entrepreneurs. Journal of Asia Entrepreneurship and Sustainability, 16(2), 21-72

Digital Competence Wheel (n.d.). An Online Testing Tool That Maps Your Digital Competences. Retrieved October 28, 2019, from https://digitalekompetencer.dk/.

Digitale, interaktive Didaktik (n.d.). Digital skills self-assessment tool for employees and managers of the Dach region. Retrieved October 28, 2019, from http://www.forum-did.de/digcomp.

Dingel, J. I., \& Neiman, B. (2020). How many jobs can be done at home? (No. w26948). National Bureau of Economic Research.

Durkin, M., McGowan, P., \& McKeown, N. (2013). Exploring social media adoption in small to mediumsized enterprises in Ireland. Journal of Small Business and Enterprise Development.

EC. (2015). A Digital Single Market Strategy for Europe-Analysis and Evidence-Commission Staff Working Document.

EC. (2016b). European Commission. Digital Economy and Society Index (DESI). Retrieved October 28, 2019, from https://ec.europa.eu/digital-single-market/en/desi. 
Engelhardt, L., Goldhammer, F., Naumann, J., \& Frey, A. (2017). Experimental validation strategies for heterogeneous computer-based assessment items. Computers in Human Behavior, 76, 683-692

ENTRECOM4ALL (n.d.). EntreCom4All, enhancing your entrepreneurship competences. Retrieved October 28, 2019, from http://entrecom4all.eu/.

Eurofound, . (2016). What do Europeans do at work? A task-based analysis: European Jobs Monitor 2016. Publications Office of the European Union.

Eurofound and the International Labour Office (2017), Working anytime, anywhere: The effects on the world of work, Publications Office of the European Union, Luxembourg, and the International Labour Office, Geneva.

European Commission. (2019). Erasmus+ Programme Guide. Retrieved October 28, 2019, from https://ec. europa.eu/programmes/erasmus-plus/resources/documents/treoirleabhar-erasmus-2019_en

European Commission. (2016). A new skills agenda for Europe: Working together to strengthen human capital, employability and competitiveness.

European Commission. (2017b). The digital skills and jobs coalition. https://ec.europa.eu/digital-singlemarket/en/digital-skills-jobscoalition.

European Commission. (n.d.). European multilingual classification of Skills, Competences, Qualifications and Occupations (ESCO). Retrieved October 28, 2019, from https://ec.europa.eu/esco/portal/home.

European Parliament and the Council. (2006). Recommendation of the European Parliament and of the Council of 18 December 2006 on key competences for lifelong learning. Official Journal of the European Union, L394/310.

European Parliament and the Council. (2008b). Recommendation of the European Parliament and of the Council on the establishment of the European Qualifications Framework for lifelong learning. Official Journal of the European Union, C111/111.

Eurostat. (2017). Digital economy and society statistics-households and individuals. https://ec.europa.eu/ eurostat/statistics-explained/index.php/Digital_economy_and_society_statistics_-_households_and_ individuals.

Evangelinos, G., \& Holley, D. (2014). Developing a digital competence self-assessment toolkit for nursing students. In Proceedings of the EDEN 2014 annual conference, from education to employment and meaningful work with ICT E-learning at work and the workplace.

Evans, D. S., \& Schmalensee, R. (2016). Matchmakers: The new economics of multisided platforms. Harvard Business Review Press.

Felstead, A., \& Henseke, G. (2017). Assessing the growth of remote working and its consequences for effort, well-being and work-life balance. New Technology, Work and Employment, 32(3), 195-212

Ferrari, A. (2012). Digital competence in practice: An analysis of frameworks. Sevilla: JRC IPTS. https:// doi.org/10.2791/82116.

Ferrari, A. (2013). DIGCOMP: A framework for developing and understanding digital competence in Europe. Publications Office of the European Union.

Garrett, R. K., \& Danziger, J. N. (2007). Which telework? Defining and testing a taxonomy of technologymediated work at a distance. Social Science Computer Review, 25(1), 27-47

Gilbert, N. (2019). 20 Best Office Software Solutions in 2019. FinancesOnline. https://financesonline.com/ office-software/.

Global Entrepreneurship Monitor. (2018). Retrieved October 28, 2019, from https://www.gemconsortium. org/report/50012.

Greiff, S., Wüstenberg, S., \& Avvisati, F. (2015). Computer-generated log-file analyses as a window into students' minds? A showcase study based on the PISA 2012 assessment of problem solving. Computers \& Education, 91, 92-105

Guillén-Gámez, F. D., Mayorga-Fernández, M. J., \& Álvarez-García, F. J. (2018). A study on the actual use of digital competence in the practicum of education degree. (pp. 1-18). Technology.

Haddon, L., \& Brynin, M. (2005). The character of telework and the characteristics of teleworkers. New Technology, Work and Employment, 20(1), 34-46

Haladyna, T. M., Downing, S. M., \& Rodriguez, M. C. (2002). A review of multiple-choice item-writing guidelines for classroom assessment. Applied Measurement in Education, 15(3), 309-333

Handel, M. J. (2016). The O* NET content model: Strengths and limitations. Journal for Labour Market Research, 49(2), 157-176

Hair, N., Wetsch, L.R., Hull, C.E., Perotti, V. \& Hung, Y.T.C. (2012). Market orientation in digital entrepreneurship: advantages and challenges in a Web 2.0 networked world. International Journal of Innovation and Technology Management, Vol. 9 No. 6, pp. 1-17.

Harmer, B. M., \& Pauleen, D. J. (2012). Attitude, aptitude, ability and autonomy: The emergence of 'offroaders', a special class of nomadic worker. Behaviour \& Information Technology, 31(5), 439-451 
Hayter, C. S., Lubynsky, R., \& Maroulis, S. (2017). Who is the academic entrepreneur? The role of graduate students in the development of university spinoffs. The Journal of Technology Transfer, $42(6), 1237-1254$

Hull, C. E., Hung, Y.-T.C., Hair, N., Perotti, V., \& De Martino, R. (2007). Taking advantage of digital opportunities: a typology of digital entrepreneurship. International Journal of Networking and Virtual Organisations, 4(3), 290-303

$\mathrm{IC}^{3}$ (n.d.). Certiport Internet and Computing Core Certification. Retrieved October 28, 2019, from https://certiport.pearsonvue.com/Certifications/IC3/.

IKANOSTEST (n.d.). Digital competences self-diagnosis test. Retrieved October 28, 2019, from https:// www.ikanos.eus/en/.

Iñiguez-Berrozpe, T., \& Boeren, E. (2019). Twenty-first century skills for all: Adults and problem solving in technology rich environments. (pp. 1-23). Technology.

ICDL (n.d.) International Computer Drivers Licence. Retrieved October 28, 2019, from https://icdl.org/.

Janssen, J., Stoyanov, S., Ferrari, A., Punie, Y., Pannekeet, K., \& Sloep, P. (2013). Experts' views on digital competence: Commonalities and differences. Computers and Education, 68, 473-481. https://doi.org/10.1016/j.compedu.2013.06.008

Kluzer, S., \& Priego, L. P. (2018). DigComp into action: Get inspired, make it happen. A user guide to the European Digital Competence Framework (No. JRC110624). Joint Research Centre (Seville site).

Kruger, J., \& Dunning, D. (1999). Unskilled and unaware of it: How difficulties in recognizing one's own incompetence lead to inflated self-assessments. Journal of Personality and Social Psychology, 77(6), 1121

Kuo, C. Y., \& Wu, H. K. (2013). Toward an integrated model for designing assessment systems: An analysis of the current status of computer-based assessments in science. Computers \& Education, 68, 388-403

Laanpere, M. (2019). Recommendations on Assessment tools for monitoring digital literacy within UNESCO's Digital Literacy Global Framework. Information Paper No, 56.

Law, N. W. Y., Woo, D. J., de la Torre, J., \& Wong, K. W. G. (2018). A Global Framework of Reference on Digital Literacy Skills for Indicator 4.4. 2.

Litchfield, B. C., \& Dempsey, J. V. (2015). Authentic assessment of knowledge, skills, and attitudes. New Directions for Teaching and Learning, 142(142), 65-80

Mahler, J. (2012). The telework divide: Managerial and personnel challenges of telework. Review of Public Personnel Administration, 32(4), 407-418

Marsh, E. (2018). Understanding the effect of digital literacy on employees' digital workplace continuance intentions and individual performance. International Journal of Digital Literacy and Digital Competence (IJDLDC), 9(2), 15-33

McCallum, E., Weicht, R., McMullan, L., \& Price, A. (2018). EntreComp into action-Get inspired, make it happen: A user guide to the European Entrepreneurship Competence Framework (No. JRC109128). Joint Research Centre (Seville site).

McIntyre, D. P., \& Srinivasan, A. (2017). Networks, platforms, and strategy: Emerging views and next steps. Strategic management journal, 38(1), 141-160

Microsoft Digital Literacy Standard Curriculum (n.d.). Retrieved October 28, 2019, from https://www. microsoft.com/es/digitalliteracy/curriculum4.aspx.

Millán, J. M., Lyalkov, S., Burke, A., Millán, A., \& van Stel, A. (2019). 'Digital divide' among European entrepreneurs: Which types benefit most from ICT implementation?. Journal of Business Research.

Mohammadyari, S., \& Singh, H. (2015). Understanding the effect of e-learning on individual performance: The role of digital literacy. Computers \& Education, 82, 11-25

MuSA (n.d.). Museum Sector Alliance project. Retrieved October 28, 2019, from http://www.projectmusa.eu.

Nambisan, S. (2017). Digital entrepreneurship: Toward a digital technology perspective of entrepreneurship. Entrepreneurship Theory and Practice, 41(6), 1029-1055

Nambisan, S., Siegel, D., \& Kenney, M. (2018). On open innovation, platforms, and entrepreneurship. Strategic Entrepreneurship Journal, 12(3), 354-368

Newman, D. (2016). Is mobility the answer to better employee productivity? Forbes. https://www.forbes. com/sites/danielnewman/2016/03/29/is-mobility-the-answer-to-better-employee-productivity/\# $7075 \mathrm{a} 0 \mathrm{ce} 131 \mathrm{c}$.

Oggero, N., Rossi, M. C., \& Ughetto, E. (2019). Entrepreneurial spirits in women and men. The role of financial literacy and digital skills. Small Business Economics, 1-15.

Olsson, A. K., \& Bernhard, I. (2020). Keeping up the pace of digitalization in small businesses-Women entrepreneurs' knowledge and use of social media. International Journal of Entrepreneurial Behavior \& Research. 
Organisation for Economic Co-operation and Development (OECD). (2019). OECD skills outlook 2019: Thriving in a digital world. OECD.

Osborne, R., Dunne, E., \& Farrand, P. (2013). Integrating technologies into “authentic' assessment design: an affordances approach. Research in Learning Technology, 21.

Pajares, F., \& Graham, L. (1999). Self-efficacy, motivation constructs, and mathematics performance of entering middle school students. Contemporary educational psychology, 24(2), 124-139

Peterson, N. G., Mumford, M. D., Borman, W. C., Jeanneret, P. R., Fleishman, E. A., Levin, K. Y., \& Gowing, M. K. (2001). Understanding work using the Occupational Information Network (O* NET): Implications for practice and research. Personnel Psychology, 54(2), 451-492

PIX. (n.d.). Online platform for digital skills evaluation and certification. Retrieved October 28, 2019, from https://pix.fr/.

Plath, J., \& Leiss, D. (2018). The impact of linguistic complexity on the solution of mathematical modelling tasks. ZDM Mathematics Education, 50(1-2), 159-171

REACT. (n.d.). Reinforcing Entrepreneurship in Adults through Communication Technologies. Retrieved October 28, 2019, from https://www.reactproject.online/.

Sahut, J. M., Iandoli, L., \& Teulon, F. (2019). The age of digital entrepreneurship. Small Business Economics, $1-11$.

Schallenmueller, S. (2016). Smart workplace technology buzz. In the impact of ICT on work (pp. 127-150). Springer, Singapore.

Schwab, K. (2018). The Future of Jobs Report. (pp. 1-133). World Economic Forum.

Scuotto, V., \& Morellato, M. (2013). Entrepreneurial knowledge and digital competence: Keys for a success of student entrepreneurship. Journal of the Knowledge Economy, 4(3), 293-303

Shute, V. J., \& Rahimi, S. (2017). Review of computer-based assessment for learning in elementary and secondary education. Journal of Computer Assisted Learning, 33(1), 1-19

Siddiq, F., Hatlevik, O. E., Olsen, R. V., Throndsen, I., \& Scherer, R. (2016). Taking a future perspective by learning from the past-A systematic review of assessment instruments that aim to measure primary and secondary school students' ICT literacy. Educational Research Review, 19, 58-84

Siegel, K., \& Hadi, K. (2017). Articulate Storyline 3 \& 360: The Essentials. IconLogic.

Sireci, S., \& Faulkner-Bond, M. (2014). Validity evidence based on test content. Psicothema, 26(1), 100-107

SMARTIVEMAP. (n.d.). A digital competence mapping tool to start digital transformation. Retrieved October 28, 2019, from https://www.smartive.company/smartivemap-test-en.

Sostero, M., Milasi, S., Hurley, J., Fernandez-Macias, E., \& Bisello, M. (2020). Teleworkability and the COVID-19 crisis: a new digital divide?. European Commission, Seville, JRC121193.

Sparks, J. R., Katz, I. R., \& Beile, P. M. (2016). Assessing digital information literacy in higher education: A review of existing frameworks and assessments with recommendations for next-generation assessment. ETS Research Report Series, 2016(2), 1-33

Srinivasan, A., \& Venkatraman, N. (2018). Entrepreneurship in digital platforms: A network-centric view. Strategic Entrepreneurship Journal, 12(1), 54-71

Steininger, D. M. (2019). Linking information systems and entrepreneurship: A review and agenda for ITassociated and digital entrepreneurship research. Information Systems Journal, 29(2), 363-407

Stödberg, U. (2012). A research review of e-assessment. Assessment \& Evaluation in Higher Education, 37(5), 591-604

Sussan, F., \& Acs, Z. J. (2017). The digital entrepreneurial ecosystem. Small Business Economics, 49(1), 59-73

The Digital Skills Gap in Europe. (2017). Factsheets. Digital skills in Europe. http://ec.europa.eu/newsr oom/dae/document.cfm?doc_id=47880. Accessed October 28, 2019.

Timmis, S., Broadfoot, P., Sutherland, R., \& Oldfield, A. (2016). Rethinking assessment in a digital age: Opportunities, challenges and risks. British Educational Research Journal, 42(3), 454-476

TUCERTICYL. (n.d.). The new digital competence certification system in Castilla León. Retrieved October 28, 2019, from https://tucerticyl.es/.

UNESCO Institute for Statistics (UIS). (2019). Recommendations on assessment tools for monitoring digital literacy within UNESCO's Digital Literacy Global Framework.

Van Deursen, A. J., \& Helsper, E. J. (2015). The third-level digital divide: Who benefits most from being online?. In Communication and information technologies annual (pp. 29-52). Emerald Group Publishing Limited.

Van Deursen, A. J., Helsper, E. J., \& Eynon, R. (2016). Development and validation of the Internet Skills Scale (ISS). Information, Communication \& Society, 19(6), 804-823

Vargas-Llave, O., Mandl, I., Weber, T., \& Wilkens, M. (2020). Telework and ICT-based mobile work: Flexible working in the digital age. Publications Office of the European Union. 
Voogt, J., Erstad, O., Dede, C., \& Mishra, P. (2013). Challenges to learning and schooling in the digital networked world of the 21st century. Journal of Computer Assisted Learning, 29(5), 403-413. https:// doi.org/10.1111/jcal.12029

Voogt, J., \& Roblin, N. P. (2012). A comparative analysis of international frameworks for 21st century competences: Implications for national curriculum policies. Journal of Curriculum Studies, 44(3), 299-321

Vuorikari, R., Punie, Y., Carretero Gomez S., Van den Brande, G. (2016). DigComp 2.0: The Digital Competence Framework for Citizens. Update Phase 1: The Conceptual Reference Model (No. JRC101254). Joint Research Centre (Seville site).

World Economic Forum. (2017). Accelerating workforce reskilling for the fourth industrial revolution: An agenda for leaders to shape the future of education, gender and work. World Economic Forum.

WOW. (n.d.). We are dreamers, we are shapers, we are what we want to be!. Retrieved October 28, 2019, from https://uwawme.eu/.

Yunis, M., Tarhini, A., \& Kassar, A. (2018). The role of ICT and innovation in enhancing organizational performance: the catalysing effect of corporate entrepreneurship. Journal of Business Research, 88, 344-356

Zamfir, A. M., \& Aldea, A. B. (2020). Digital Skills and Labour Market Resilience. Postmodern Openings/ Deschideri Postmoderne, 11.

Publisher's Note Springer Nature remains neutral with regard to jurisdictional claims in published maps and institutional affiliations. 